\title{
A Network Based Approach to Evaluate Participatory Policy Processes: An Application to CAADP in Malawi
}

\author{
Christian Henning and Eva Krampe
}

\section{Introduction}

Donor organizations recently engaged in promoting participatory policy processes as a tool for designing efficient policy programs. Participatory policymaking is a process through which stakeholders influence and share control over prioritysetting and policymaking (World Bank 2011). The implementation of participatory processes is promoted to increase the efficiency and effectiveness of policy choices, particularly in developing countries. In general, more effective and efficient policy choices are induced via specific mechanisms: 1. Increasing governmental accountability (Keefer and Khemani 2005) (i.e., incentives for governmental agents to serve societal interests and needs). 2. Reducing government capture (Bardhan and Mookherjee 2002) (i.e., government incentives to serve vested interests at the expense of the general public). 3. Increasing evidence-based policy processes (i.e., the degree to which political actors use available political knowledge for making policy choices. Political knowledge is knowledge about the technical relation between policies and induced policy outcomes). 4. Increasing policy ownership (i.e., citizens [civil society] identify with and feel committed to governmental policy); policy ownership implies a higher citizen compliance with the established policy framework and can significantly reduce political implementation costs (Adserà et al. 2003; Jones 2013; Chambote and Shankland 2011).

Any opinions stated herein are those of the authors and do not necessarily reflect the policies or opinions of EIB.

C. Henning

Department of Agricultural Economics, University of Kiel, Kiel, Germany

E. Krampe $(\bowtie)$

European Investment Bank, Luxembourg, Luxembourg

e-mail: e.krampe@eib.org

C. Henning et al. (eds.), Development Policies and Policy Processes in Africa, 
Accordingly, it is widely accepted that the ownership of policy programs that occurs as a result of participation in policy program formulation leads to more effective implementation and adoption of the policy programs (World Bank 2011).

Understanding the nature of participatory policy processes is not only high on the research agenda at the academic level but also increasingly recognized as a key condition for efficiently providing support for the formulation of effective policy programs in political practice. The Comprehensive Africa Agriculture Development Programme (CAADP), which was initiated by the African Union, is a good example of these new developments. The inclusion of local stakeholder organizations in the planning, formulation and evaluation of sector-specific growth policies is a key principle of the program (NEPAD 2010). However, a CAADP task group focused on the evaluation of non-state actor participation reported that stakeholders had only a limited ability to use the newly created opportunities for participation. Based on information collected via a qualitative stakeholder survey and desk research, the task group emphasized that CAADP has not yet consistently achieved a high quality inclusion of non-state actors at the national, regional or local levels (Randall 2011, p. 2).

Nevertheless, although participatory policy processes are intuitively convincing as a tool for the evaluation of existing policy processes and for the design of more efficient policy processes in the future, the development of a measurement tool that allows for the comprehensive characterization of participation structures inherent to real policy processes that are ongoing in political practice is necessary. Ideally, this measurement tool is grounded in political theory to guarantee that empirically identified participation structures can be consistently related to an intervention logic (i.e., the derivation of a causal link between specific properties of the policy process and desirable policy outcomes). The latter criterion implies that the impact of the identified structures of a policy process on governmental accountability and capture and on the effective use of political knowledge and political ownership can be directly derived.

However, to the best of our knowledge, a comprehensive, micro-politicalfounded and quantitative evaluation framework for participatory policy processes is not currently available. In this context, the Advocacy Coalition Framework (ACF) proposed by Sabatier and Jenkins-Smith (1993) has attracted attention as an approach for analyzing policy processes, particularly among political scientists at the academic level. More recently, the ACF has been increasingly recognized by development economists (Birner and Resnick 2010). This framework includes a number of interesting aspects (e.g., this framework explicitly identifies beliefs as drivers of coalition formation and final political decisionmaking). Moreover, this framework provides a systematic approach for analyzing stakeholder interactions. However, the ACF is a qualitative approach and provides neither a theoretical model of political decisionmaking nor a theoretical model of belief formation among the actors involved in policymaking. In particular, a quantitative description of real policy processes is a necessary condition for a comprehensive evaluation of the impact of these processes on the effectiveness and efficiency of policy outputs. Hence, the ACF in its present form is not yet an appropriate tool for policy learning (i.e., a tool that is ready to identify causal links between specific patterns of stakeholder interactions and induced governmental performance). 
In this context, the aim of this chapter is to initiate the development of a theoretically founded framework for analyzing participatory policy processes that can be applied empirically. In particular, following the literature on policy network analyses (Lauman and Knoke 1987; Pappi et al. 1995; Knoke et al. 1996; Pappi and Henning 1998, 1999; Henning 2000, 2009), we apply social network analysis (SNA) to measure complex interactions among stakeholder and governmental organizations. Moreover, we derive a theoretical framework for the incorporation of policy network theory into political economy models of lobbying and legislative decisionmaking. As we demonstrated in Chapter "Modeling and Evaluation of Political Processes: A New Quantitative Approach", we incorporate a network model of political belief formation into a political bargaining model (see Henning in this volume). The latter model combines a generalized Grossman-Helpman lobbying model and a modified legislative bargaining model of the Baron and Ferejohn type. The central component of such an integrated model corresponds to a generalized mean voter decision rule, where in addition to legislators, interest groups also have political control over policies (Pappi and Henning 1998; Henning 2000, 2009). Political control of nongovernmental organizations results via two different mechanisms: lobbying and communication learning. The first mechanism is determined by the political access structures via which nongovernmental organizations access powerful governmental organizations, and the second mechanism is determined by political communication among organizations. Empirically, the equilibrium outcome of the complete model can be derived from observed political support and communication networks.

Based on our theoretical framework, we undertake a descriptive analysis of the central components that determine policy choices. This analysis includes a network analysis of the underlying communication and access structure, which is encapsulated in the communication network and the political support network. In this regard, social network analyses provide a wide range of local and global network tools and methods for describing the characteristics of an individual network (Wassermann and Faust 1994). Previous political sociology reports demonstrated that network analysis can be used to systematically describe interaction structures among nongovernmental and governmental organizations that are engaged in a specific policy domain (Lauman and Knoke 1987; Knoke et al. 1996; Pappi et al. 1995; Pappi and Henning 1998, 1999; Henning 2000; Henning and Wald 2000). However, with a small number of exceptions (e.g., Pappi and Henning 1998; Henning 2000, 2009), these studies used SNA to describe policy domain network structures without relating the identified structures to political performance. In contrast, our framework offers innovative network tools (i.e., the network multipliers derived in Chapter "Modeling and Evaluation of Political Processes: A New Quantitative Approach") that go beyond a pure descriptive analysis. The framework will allow us to make direct conclusions concerning the impact of the identified network structures on different aspects that determine governmental performance. Specifically, we describe the four previously mentioned aspects of government performance and use our network-based indicators to measure these factors empirically. 
The case country selected for the empirical application of our framework is Malawi. Malawi approved a policy reform, the sector investment program Agricultural Sector Wide Approach (ASWAp), based on the principles of CAADP in 2010. Data was collected via a policy network study in 2010.

In the next section, we briefly summarize the theoretical framework for modeling participatory policy processes. We describe in detail the design of the network study, including the collected data and the central network theoretical tools/measures used in our analyses. We then present the principal empirical results, and we conclude by providing an outlook on future research.

\section{A Theoretical Framework for Evaluating Policy Processes}

In general, we apply the theoretical framework developed in Chapter "Modeling and Evaluation of Political Processes: A New Quantitative Approach". We focus specifically on the combination of a modified legislative bargaining model and the political belief formation model in a policy elite network. This approach considers the political decisionmaking process as an aggregation mechanism of the policy preferences of the involved political actors. In essence, this aggregation mechanism corresponds to a generalized mean voter decision rule:

$$
\gamma^{*}=\sum_{j} \varphi_{j}^{T} \widehat{\gamma}_{j}^{0}
$$

where $\gamma^{*}$ denotes the final policy decision, $\varphi_{j}^{T}$ denotes the total political power and $\widehat{\gamma}_{j}^{0}$ denotes the initial preferred policy position of actor $\mathrm{j}$. The total political power results from political influence on powerful political actors:

$$
\varphi_{j}^{T}=\sum_{i} \bar{m}_{i j} \varphi_{i}^{L}
$$

where $\bar{m}_{g j}$ denotes the political influence of actor $\mathrm{j}$ on agent $\mathrm{i}$. As demonstrated in Chapter "Modeling and Evaluation of Political Processes: A New Quantitative Approach", $\bar{m}_{g j}$ is the network multiplier derived from the communication network among governmental and nongovernmental actors. Accordingly, $\bar{m}_{g g}$ denotes the weight that a legislator $g$ puts on her own initial position, while $\varphi_{i}^{L}$ is the political power of agent $i$ that is derived from the lobbying game, as described in Chapter "Modeling and Evaluation of Political Processes: A New Quantitative Approach". Thus, it holds:

$$
\varphi_{i}^{L}=\sum_{g} m_{g i}^{S} \varphi_{g}
$$


As described in Chapter "Modeling and Evaluation of Political Processes: A New Quantitative Approach", $m_{g i}^{S}$ is the support network multiplier that corresponds to the outflow of legislative power from legislator $g$ to actor $i$, resulting in the equilibrium of the lobbying game. Hence, the better access an interest group $i$ has to powerful legislators, the more successful are the lobbying activities of this organization. Further, $\varphi_{g}$ denotes the legislative power of legislator $g$ that is derived from the modified legislative bargaining game, as described in Chapter "Modeling and Evaluation of Political Processes: A New Quantitative Approach". Equations (1, 2, and 3 ) constitute the theoretical backbone of our policy process framework, which we have also illustrated in Fig. 1 below.

As is illustrated in Fig. 1, based on our theory, the policy process corresponds to an aggregation mechanism of the policy positions of the involved governmental and nongovernmental organizations, where the individual weight of an organization is jointly determined by political communication network structures that determine political influence $\bar{m}_{i j}$, informal access structures $\bar{m}_{g i}^{S}$ that determine lobbying power and constitutional rules that determine legislative decisionmaking power $\varphi_{g}{ }^{1}$.

Based on our theoretical framework, the underlying communication and access structures, which are encapsulated in the communication network MC and the political support network MS, are central components that determine final policy choices. To describe these networks, we apply social network analysis tools, including methods for identifying overall network structures (e.g., block model analysis) (Wassermann and Faust 1994). However, our framework offers innovative network tools that go beyond a pure descriptive analysis to allow us to draw direct conclusions concerning the impacts of the identified network structures on different aspects that determine governmental performance (i.e., the network multipliers derived in Chapter "Modeling and Evaluation of Political Processes: A New Quantitative Approach". Specifically, we develop the network-based indicators

Fig. 1 Overview of the framework. Source: Authors

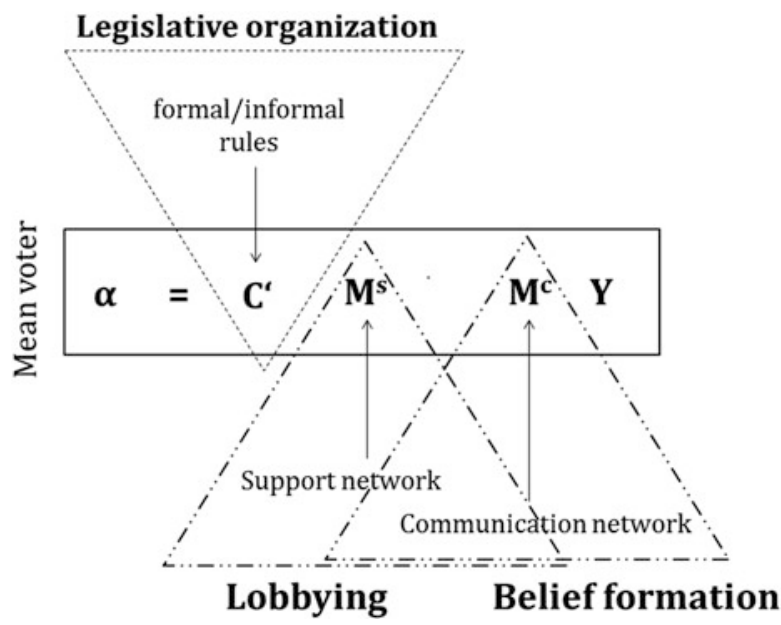


described below to empirically measure different aspects of governmental performance.

\subsection{Government Accountability}

The successful functioning of any government depends on the ability of citizens to hold politicians and public administrators accountable for their actions. The existing literature on political accountability describes the machinery of government as a game between a principal (i.e., the public) and an agent (i.e., the politicians or public administrators) in which the former delegates to the latter a given set of instruments to execute certain goals (Adserà et al. 2003). In this game, the principal and the agent may have opposing interests (i.e., even while partially acting based on the interests of their potential electorate, political agents are likely to pursue their own political agenda [e.g., political agents may be interested in enriching themselves while in office or political agents' strategies for enhancing the welfare of the public may differ from the desires of the public]). Hence, with selfinterested political agents, the delegation of decisionmaking and policy implementation responsibilities automatically provides the opportunity for significant inefficiencies and corruption among politicians. One could argue that electoral competition induces governmental incentives for acting in line with society's interests; thus, the high concentration of political power in governmental organizations does not contradict political accountability. Though this argument could be true in general, this reasoning is limited because elections fail to guarantee/imply strong governmental accountability. The citizens' (i.e., voters') information concerning governmental policies and their consequences for society's welfare is a factor that impacts the functioning of free and regular democratic elections as an effective mechanism for guaranteeing political accountability. If citizens lack this information, they base their votes on non-policy indicators. As demonstrated in Chapter "Voter Behavior and Government Performance in Malawi: An Application of a Probabilistic Voting Model", this statement is especially true for Malawi, where non-policy voting motives are the principal determinants of vote choices, particularly within the rural population. Thus, voters are swayed by the relative campaign spending of different parties, which reflects the influence of election advertisements more than high governmental performance (i.e., serving voters' true desires and needs). Hence, in addition to elections, the participation of stakeholder organizations in the political process is a second mechanism for holding public officials accountable. The more domestic stakeholder organizations control governmental actions and policy choices via lobbying and political communications, the more these actions and choices correspond to the desires of society.

Therefore, we use the sum of the total political power of national nongovernmental organizations (NGO) as a general indicator of government accountability (GA-total): 


$$
G A-\text { total }=\sum_{j \in N G O} \varphi_{j}^{T}
$$

Moreover, to understand how policy network structures interact with constitutional rules, we use the power outflows from central political institutions to national NGOs (i.e., from the government, including the president and the ministries, and from the parliamentary parties) as two additional sub-indicators of governmental accountability (i.e., GA-Gov and GA-Par, respectively).

\subsection{Government Capture}

According to the relevant political economy literature (Bardhan and Mookherjee 2002), governmental capture corresponds to the concept that governmental political actions and policy choices are biased towards the particular interests of organized social groups at the expense of the general public. Thus, even if the government is fully accountable to its electorate, it might respond asymmetrically to the specific interests of particular social groups. In this context, electoral competition induces governmental capture because some social groups are less informed than others (see also Chapter "Voter Behavior and Government Performance in Malawi: An Application of a Probabilistic Voting Model"). However, beyond democratic elections, stakeholder participation is a second channel/mechanism for relaying society's interests to public officials. Hence, the determination of the extent to which this mechanism is biased in favor of the particular interests of vested groups is of interest. Accordingly, we calculate the quadratic distance between the relative total political power of a stakeholder organization and its corresponding share of represented society members in the total population $P o p_{j}$ and take the square root of the sum of these distances over all relevant stakeholder organizations as an indicator of capture (GC-total):

$$
G C-\text { total }=\sqrt{\sum_{j \in G N O}\left[\frac{\varphi_{j}^{T}}{\sum_{k \in N G O} \varphi_{k}^{T}}-P_{o p}\right]^{2}}
$$

To guarantee that our capture index GC lies in the $[0,1]$ interval, we normalize GC as follows: $G C^{n}=\frac{G C}{G C+1}$. Further, we take the square root of the sum of the calculated distances for specific population subgroups that represent specific interests (e.g., small-, medium- and large-scale farmers or urban consumers) as sub-indicators of capture, namely GC-farm and GC-urban. 


\subsection{Political Knowledge}

Understanding the complex relation between policy instruments and induced policy outcomes is difficult; thus, politicians use simple mental models (i.e., political beliefs) to describe the manner in which policies translate into outcomes. Because voters, politicians, and lobby and stakeholder organizations fail to fully understand the complex relation between political instruments and desired policy outcomes, inefficient policy choices are implied. As described in the introductory chapter of this book, an increasing number of publications emphasize the role of biased policy beliefs as a main determinant of inefficient policy choices (Beilhartz and Gersbach 2004; Bischoff and Siemers 2011; Caplan 2007). Hence, beyond biased governmental incentives caused by low accountability or high governmental capture, the lack of political knowledge becomes another important source of policy failure. As described in Chapter "Whither participation? Evaluating participatory policy processes with the CGPE approach: The case of CAADP in Malawi", the individual political knowledge of an actor can be measured by comparing the stated ideal policy positions of an organization with the optimal policy position of an organization. The latter position results from maximizing an organization's support, assuming perfect political knowledge (i.e., CAADP policies translate into policy outcomes based on the specified Computable General Political Economy Equilibirum (CGPE) model, denoting the stated and optimal policy positions by $\widehat{\gamma}_{i}$ and $\widehat{\gamma}_{i}^{o p t}$ and the Euclidian distance, which is a measure that corresponds to the error variance, as derived in Chapter "Modeling and Evaluation of Political Processes: A New Quantitative Approach", by $\psi_{i}=\left\|\widehat{\gamma}_{y}^{o p t}-\widehat{\gamma}_{i}\right\|$ ). As explained in Chapter "Modeling and Evaluation of Political Processes: A New Quantitative Approach", based on our belief updating model, comparing the total political power distribution to the distribution of political knowledge across organizations allows an assessment of the extent to which the identified participation structures promote or impede evidence-based policy processes. Moreover, we can identify power structures, $\varphi_{j}^{o p t}(\psi)$, that imply an optimal use of political knowledge in the policy network $\psi$ and calculate the loss of efficiency that results under the actual communication structure compared to the optimal communication structure. We take this relative loss as an indicator of the impact of existing policy structures on evidence-based policy (PK-use):

$$
P K-\text { use }=1-\frac{\sigma_{\varepsilon}^{2}\left(\varphi^{T}\right)}{\sigma_{\varepsilon}^{2}\left(\varphi^{o p t}\right)}=1-\frac{\sum_{j}\left[\varphi_{j}^{T}\right]^{2} \frac{\psi_{j}}{\psi_{0}}}{\sum_{j}\left[\varphi_{j}^{o p t}\right]^{2} \frac{\psi_{j}}{\psi_{0}}},
$$

$\sigma_{\varepsilon}^{2}\left(\varphi^{T}\right)$ and $\sigma_{\varepsilon}^{2}\left(\varphi^{o p t}\right)$ denote the error variance that results from the mean voter decision, assuming the actual and optimal distribution of total political power, respectively. $\frac{\psi_{j}}{\psi_{0}}$ is the relative political knowledge of an organization $\mathrm{j}$ compared to a reference organization 0. Further, we take the Euclidian Distance between the 
actual and optimal political power distribution and the sum of the total political power of the domestic research organizations as two additional sub-indicators (i.e., PK-dpow and PK-Res) of the degree of political knowledge use.

\subsection{Political Ownership}

Political ownership corresponds to the concept that a society identifies with a specific policy and is committed to accomplishing the envisaged policy goals. Hence, a lack of ownership corresponds to an incentive problem on the side of the society. Technically, ownership is related to the involvement of national nongovernmental organizations in political communication. Political ownership increases citizen compliance with policies, decreasing implementation costs and increasing the effectiveness of the implemented policies. In contrast to governmental accountability, the ability of nongovernmental organizations to exert influence on governmental organizations is less important for achieving political ownership. In contrast, even a top-down communication system (i.e., the policy beliefs of civil society are primarily influenced by governmental organizations) implies political ownership because the citizens feel involved in policy formulation. Accordingly, all other things being equal, the higher the level of consensus achieved through stakeholder participation, the higher the political ownership of citizens in the decided policies will be. To measure the political ownership implied by stakeholder participation, we define the following political conflict index from the viewpoint of an organization $\mathrm{i}(\mathrm{CONi})$ :

$$
\operatorname{CON}_{i}\left(\gamma^{*}\right)=\sqrt{\sum_{k} \theta_{i k}\left(\widehat{\gamma}_{i k}-\gamma_{k}^{*}\right)^{2}}
$$

where $\theta_{i k}$ denotes the interest of actor i in the policy dimension $\mathrm{k}, \widehat{\gamma}_{i k}$ denotes the ideal position of actor $\mathrm{i}$ with respect to dimension $\mathrm{k}$, and $\gamma_{k}^{*}$ is the final policy decision for the dimension $k$. Accordingly, the average political conflict for all national nongovernmental organizations results as:

$$
\operatorname{CON}_{N G O}\left(\gamma^{*}\right)=\sum_{j \in N G O} \operatorname{CON}_{j}\left(\gamma^{*}\right) .
$$

Hence, we can calculate the final policy outcome that would result from legislative bargaining, assuming no lobbying and no belief updating occur. Let $\gamma^{\#}$ denote this policy outcome. We can then analogously define the average political conflict $\operatorname{CON}_{N G O}\left(\gamma^{\#}\right)$. The lower the political conflict when including political communication and lobbying in comparison to the political conflict without communication, the higher the involvement of the nongovernmental organizations; thus, we define the following indicator of political ownership (PO-Consens): 


$$
P O-\text { Consens }=1-\frac{\operatorname{CON}_{N G O}\left(\gamma^{*}\right)}{\operatorname{CON}_{N G O}\left(\gamma^{\#}\right)}
$$

Further, because political ownership generally decreases with the dominance of donor organizations in the political process (Chambote and Shankland 2011; Jones 2013), we take the total political power of a donor organization as an additional sub-indicator of ownership (PO-Donor). Moreover, we use the density of the communication network between the national nongovernmental and governmental organizations as a measure of political involvement that corresponds to ownership (PO-involve). ${ }^{1}$

Overall, within our framework, we can first use standard network analysis tools to describe the interaction structures among governmental and nongovernmental organizations that are involved in the political decisionmaking process. Second, we can apply innovative network-based indicators to evaluate the extent to which the identified participation structures impact political performance (i.e., governmental accountability and capture, effective use of political knowledge and political ownership). Please note that trade-offs generally exist among the different aspects of political performance. For example, an increase in the participation of civil society organizations in political communication might increase the governmental accountability and political ownership and simultaneously decrease the effective use of political knowledge. Consistent with this reasoning, Ball (1995) demonstrated that lobbying implies a trade-off between the effective use of political knowledge and government capture. Analogously, an increase of donor involvement in political communication might increase the effective use of political knowledge while reducing political ownership and political accountability.

Finally, we must note that the empirical relevance of this assessment depends on the assumption that our theoretical model accurately describes real political decisionmaking processes. In this regard, we use the empirical prediction power of our theoretical model as a test of the empirical relevance and applicability of our framework.

\footnotetext{
${ }^{1}$ Please note that the involvement of civil society is also related to accountability. Even if stakeholder organizations monitor governmental actions without controlling these actions, accountability might be increased because stakeholders inform voters. Thus, voter choices are c.p. more informed, strengthening voters' ability to hold the government accountable. Therefore, one could also use the density of political communication between national stakeholder organizations and governmental organizations as a sub-indicator of accountability. However, in this paper, we use this factor as a sub-indicator of political ownership.
} 


\section{Analyzing the CAADP Policy Processes in Malawi}

\subsection{Policy Reform Context}

In 2010, the Malawi government approved the sector investment program Agricultural Sector Wide Approach (ASWAp) (The Ministry of Agriculture and Food Security, Republic of Malawi 2010). ASWAp is based on the principles of CAADP. The principal goal of the program is to achieve agricultural growth and poverty reduction using investments in the agricultural sector and reforms of the corresponding institutional framework as the central policy instruments. Moreover, the Government of Malawi follows the comprehensive participatory approach elaborated within CAADP (i.e., the Malawi government attempted to design a CAADP policy process characterized by high involvement of local stakeholder organizations in the design, monitoring and evaluation of all activities and policies decided within ASWAp). Thus, in addition to political actors and donor organizations, the umbrella organizations of the food security civil society organizations and farmer organizations (i.e., CISANET and FUM, respectively) signed the CAADP Compact in April 2010. Despite the potential of CADDP reform processes, the extent to which the real CAADP policy process in Malawi promotes participatory and evidence-based policies remains unclear. We apply our framework to elucidate this issue in the following sections.

\subsubsection{Study Design and Data Collection}

To collect relevant data, an elite network study was organized. Such a study involves a survey containing questions about networks, policy positions and interests. The survey was completed via personal interviews using carefully constructed survey questionnaires in May 2010. Interviews with representatives of relevant nongovernmental and governmental organizations were conducted in Lilongwe and Blantyre.

The unit of observation in an elite network study is an organization, which is interpreted as a corporative actor (Coleman 1990). The respondents are considered experts of the organizations they represent in the specific policy field. Following an established approach that is used in policy network studies, relevant organizations were identified using a two-step procedure (Laumann and Knoke 1987; Laumann et al. 1989; Pappi et al. 1995; Pappi and Henning 1999). In the first step, a list of potentially relevant organizations was compiled based on desk research and expert interviews. $^{2}$ This list included 60 nongovernmental organizations and

\footnotetext{
${ }^{2}$ In particular, we used available information concerning stakeholder participation in agricultural policy workshops published on the internet. Moreover, we used a list of stakeholder organizations, donors and politicians engaged in the formulation of the Farm Input Subsidy Programme (FISP), which was included in a previous study by IFPRI in 2010 (Aberman et al. 2012).
} 
35 governmental organizations. Based on this list, personal interviews were conducted with representatives of the preselected organizations, beginning with governmental organizations (i.e., Ministry of Agriculture and Food Security (MoAFS) and subordinate agencies) and the most important interest groups (i.e., farm organizations). A reputation question was asked during the interview, and interviewees were instructed to mark all influential organizations on the identified list. Based on the reputation question, new organizations that received more than 3 nominations were interviewed. Overall, we interviewed 17 governmental organizations and 20 nongovernmental organizations.

The elite questionnaires included three parts: (a) policy networks, (b) policy preferences (i.e., information concerning interest and position with respect to relevant ASWAp policy issues, and 9c) organizational characteristics. ${ }^{3}$ In the network portion of the questionnaire, we collected data on reputation, expert information, monitoring, social relation and organizational membership networks. To collect reliable networks, we designed our network questions using a format that was extremely helpful in previous network studies (Pappi and Henning 1999; Pappi et al. 1995). Interviewees were asked to check those organizations on the list with which they maintain a specific relation. To facilitate orientation, the list of organizations was organized according to the type of organization or the branch of interest represented by the respective organizations (see Table 5 in the appendix). ${ }^{4}$ In the following sections, we describe in more detail the reputation and expert information networks, as these networks are used for the empirical application of the proposed policy framework. Based on our theoretical framework, political support networks are also relevant. However, in the Malawi case study, we did not include political support networks in our policy network survey. Accordingly, we will simulate the support network using collected policy network data. ${ }^{5}$ Therefore, we will only briefly describe the simulated political access network structures.

As described above, the reputation network is used to specify the network boundary from the actors' point of view. Respondents were asked to mark organizations on the list that according to their opinion, stand out as especially influential with respect to the agricultural policy process. ${ }^{6}$ The expert information network is

\footnotetext{
${ }^{3}$ Data collection for part (c) is described in detail in Chapter "The Formation of Elite Communication Networks in Malawi: A Bayesian Econometric Approach".

${ }^{4}$ As we did not know in advance whether we identified all relevant organizations, we provided a hybrid type of list. That is, interviewees were presented with a roster of organizations and given the option to add additional organizations that they believed to be important. This approach addresses two problems: under-reporting in a free recall interview and failures in setting the theoretical network boundaries.

${ }^{5}$ Please note that we explicitly collect policy support network data in other empirical applications [e.g., for the European Union (Pappi and Henning 1998, 1999) and within the PEBAP-project for Ghana, Uganda and Senegal (https://pebap.agrarpol.uni-kiel.de/)].

${ }^{6}$ The question was framed in a way that instructed interviewees not to exert great effort on a detailed investigation but to mark those organizations that came to mind instantly. This framing assumes that highly important organizations will come to mind quickly. Further, the interviewees had the option to use blank lines to add missing influential organizations.
} 
the centerpiece of our belief formation model for characterizing the policy process. We consider expert information to be any kind of information about policy impacts that an actor can communicate to another actor (e.g., knowledge about the impact of farm input subsidies on central policy outcomes, such as the welfare of different social groups). To collect data on the information flow in the elite network, the interviewees were asked to check those organizations on the list of organizations with which they share information about the consequences of agricultural policies. Specifically, expert information transfers were collected from a supplier perspective (i.e., an organization delivers information to another organization) and a demander perspective (i.e., an organization receives information from another organization). Therefore, we could construct a confirmed expert knowledge network, which is more reliable from a network theoretic point of view (Pappi et al. 1995). A particular knowledge transfer is considered 'confirmed' if both the supplier and demander of knowledge independently report the transfer.

The weight that an actor places on her own initial belief is another key input in our model. To identify an actor's level of own control, interviewees were asked to ascertain the extent to which they use externally provided expert information as opposed to their own expertise when formulating policy strategies. In detail, the respondents were asked to divide 100 points to indicate the relative importance of external versus internal expert information. Own control is then calculated as the relative importance of own internal expertise.

In part (b), we collected data on the policy preferences of organizations. We asked for the relative interest and the preferred position of an organization with respect to relevant ASWAp policy issues. Specifically, we assumed a nested structure of policy preferences. At the top level, we asked for the relative interest in and preferred position regarding relevant policy concerns $z$. These policy concerns are relevant policy outcomes determined by ASWAp, including $Z 1$ the welfare of small scale-farmers, $Z 2$ poverty reduction, $Z 3$ state budget expenditures and $Z 5$ the welfare of urban consumers (see Chapter "Whither participation? Evaluating participatory policy processes with the CGPE approach: The case of CAADP in Malawi" for a full list of relevant policy concerns). At the second level, we considered interest and positions in specific policy programs formulated in ASWAp. Specifically, ASWAp includes the following four pillars, which are formulated as focus areas in official documents (The Ministry of Agriculture and Food Security, Republic of Malawi 2010): pillar I is "Food security and risk management;" pillar II is "Agri-business and market development;" pillar III is "Sustainable land and water management;" and pillar IV is "Technology generation and dissemination/Institutional strengthening and capacity building." According to the official documents for each pillar, two alternative subprograms are formulated. For example, for pillar I, the first subprogram corresponds to fertilizer subsidy payments for maize; in the alternative subprogram, input subsidies are paid for all crop production to increase the diversification of agricultural production. The subprograms of ASWAps are described in Chapter "Whither participation? Evaluating participatory policy processes with the CGPE approach: The case of CAADP in Malawi". For each pillar and each subprogram, we collected the policy positions 
preferred by an organization, where a policy position corresponds to the amount of budget expenditures allocated to a specific subprogram or pillar. To obtain a complete picture, we also included budget expenditures allocated to non-agricultural policy programs. Overall, the collected data on policy positions included the allocation of total state budget expenditures to the 8 ASWAp subprograms and to non-agricultural policy programs. Subtracting the sum of the budget expenditures for agricultural and non-agricultural policy programs from the total state budget results in the budget expenditures that are available for the provision of public goods, such as health or other social security services. Within the survey, we collected the interest $\theta$ and position $\widehat{\gamma}$ in all nine policy programs. Accordingly, we were able to derive the spatial policy preferences of individual organizations, $U_{i}(\gamma)=-\sum_{k=1}^{4} \theta_{i k}\left(\widehat{\gamma}_{i k}-\gamma_{k}\right)^{2}$. To describe the different policy preferences of organizations, we further reduce the nine-dimensional policy space to a two-dimensional policy space by applying a principal component analysis using the collected policy positions as inputs. Based on a factor loading matrix, we interpreted the first principal component as the budget allocation between agricultural and non-agricultural programs, where a high factor score on the first component implies a high budget share for agricultural programs and a negative score implies a high budget share for non-agricultural policy programs. The second component can be interpreted as a budget allocation within ASWAp programs, where a positive factor score corresponds to the reallocation of budget expenditures from pillar I (i.e., input subsidies) and to a lower extent, from pillar III (i.e., water and land policy programs) in favor of pillar II (i.e., programs promoting rural infrastructure) and pillar IV (i.e., extension services and agricultural research). The positions of individual organizations in the two-dimensional macro-policy space are presented in Fig. 9 below.

\section{Analyzing the CAADP Policy Process in Malawi: A Network Approach}

\subsection{Relevant Organizations in the CAADP Policy Domain}

Table 5 in the appendix lists the 37 interviewed organizations and their indegree centrality in the reputation network. The indegree centrality summarizes an organization's received nominations, which are standardized by the number of maximal possible nominations (Wassermann and Faust 1994). Overall, our sample represents the top most influential organizations in Malawi, and MoAFS stands out as an especially influential organization, with a maximal indegree centrality of 1 .

In Table 5, the stakeholder organizations are further subordinated into different categories according to the social groups they represent. In detail, we consider farmer (farm), agribusiness (AB) and non-agricultural interest group (NA) organizations, as well as research (RES) and civil society organizations. 
The latter group includes consumer (con) and church organizations (chur). To facilitate the presentation of the results of our network analyses, we combine the civil society organizations and the NA organizations into one civil society category (CSO) in the following section.

\subsection{Identified Network Structures of Political Participation in Malawi}

\subsubsection{Political Communication}

Political communication in the CAADP policy domain is comparatively intensive, with a global density of 0.23 for the confirmed expert network. For example, in the policy domain of the European Common Agricultural Policy of the EU-27, the confirmed expert network exhibited a global network density of only 0.11 ; even for the EU-15, the corresponding density is only 0.14 (Henning 2009).

However, a block model analysis of the political communication network ${ }^{7}$ reveals that political communication is clearly structured in Malawi, with a political core (i.e., block 1) that includes central governmental organizations and donor organizations and a political periphery (i.e., block 3) comprised of primarily national civil society organizations (see Fig. 2 and Table 5).

Interestingly, in addition to the leading ministries that determine agricultural policy in Malawi (i.e., MoAFS and Ministry of Finance [MoF]), all seven donor organizations are part of the political core. In contrast, the only national nongovernmental organizations that are part of the political core are the two agribusiness interest groups (i.e., Farmer's world and STAM) and the national peak civil society organization CISANET. The farm interest group FUM in block 4 plays a key role in political communication. This interest group is highly integrated in political communication and functions as a broker between the civil society periphery and the political core. A second broker block (i.e., block 2) that connects civil society with the political core is formed around Bunda College, which is the main research organization involved in the CAADP process. In addition to Bunda College, block 2 also includes the public agency ADD and the ministry of irrigation and water development (MoIWD). Given the specific composition of blocks 2 and 4, block 2 can be interpreted as a technical leader, and FUM functions as the central political link connecting the political core to the civil society periphery. Please note that the periphery is not only weakly connected with the political core, as indicated by a density of only 0.12 between block 1 and

\footnotetext{
${ }^{7} \mathrm{~A}$ block model analysis identifies actors in a network that are structurally equivalent (i.e., they have the same pattern of relation to all other actors in the network). Structurally equivalent actors are grouped into the same block, where members have a specific relational pattern to other blocks. Please note that in contrast to a cluster analysis, block members are not necessarily related to each other (Wassermann and Faust 1994).
} 


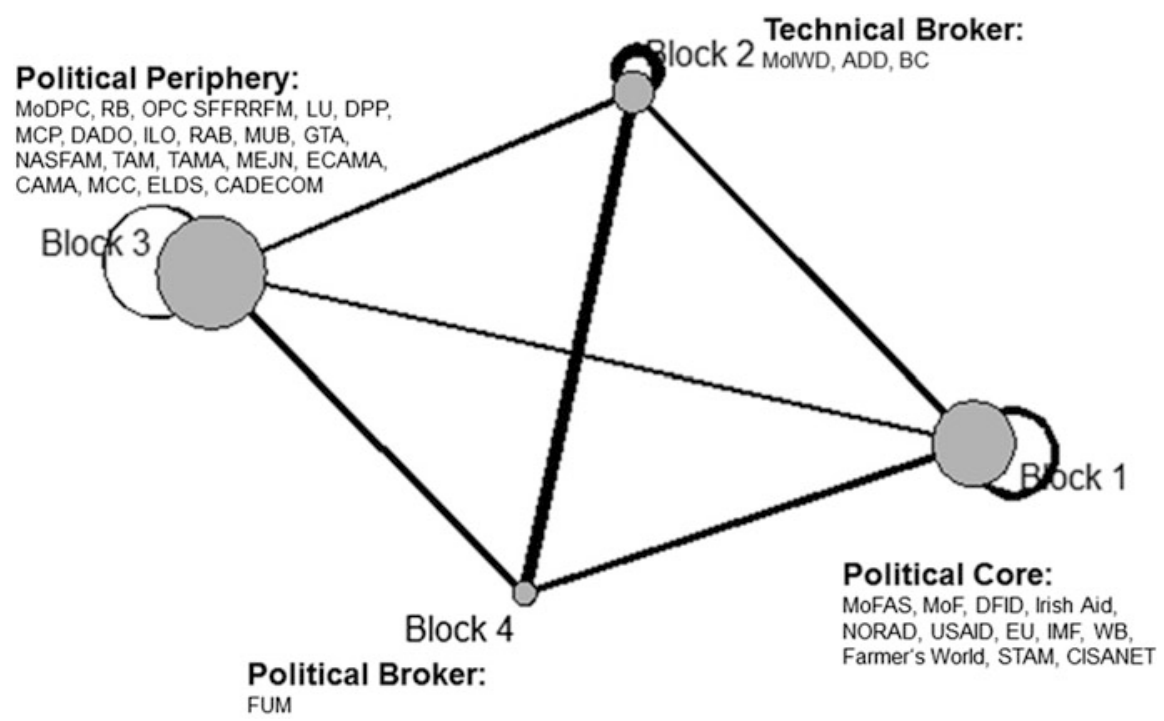

Fig. 2 Block model structure of political communication in Malawi. Source: Authors

3 , but even internally peripheral organizations do not communicate with each other very much, as indicated by an internal density of only 0.11 for block 3 (see Table 1 ). The office of the president (OPC) is a key player within the periphery. The OPC is central within the internal communication of the political periphery, as it is connected to over $30 \%$ of the organizations in the periphery. Moreover, the OPC is a strategic link between the periphery and the political core, as it is connected to the political brokers (i.e., blocks 2 and 4) and to MoF in the political core.

\subsubsection{Lobbying}

According to our modified Grossman-Helpman model, the central determinant of lobbying power is the access of an organization to powerful politicians. Empirically relevant access structures are identified via political support networks. Following Pappi and Henning (1999), we focus on direct access, leaving the analysis of indirect brokerage relations for future work (Henning 2009). The densities of the support network are reported in Table 2. As demonstrated in Table 2, donor organizations have good access to the most powerful governmental organizations, especially MoF and MoAFS, but national stakeholders only have access to MoAFS, MoIWD and the president (i.e., OPC). Interestingly, access to legislative parties is dominated by national stakeholder organizations, primarily CSO, and farm organizations; donors have no access to legislative parties. Moreover, political institutions depend on their mutual political support, and most political institutions exhibit relatively high densities above 0.5 (see Table 2). The mutual dependence of the 
Table 1 Block densities of the political communication network in Malawi

\begin{tabular}{l|l|l|l|l}
\hline & Block 1 & Block 2 & Block 3 & Block 4 \\
\hline Block 1 & 0.56 & 0.39 & 0.12 & 0.42 \\
\hline Block 2 & 0.39 & 1.00 & 0.37 & 1.00 \\
\hline Block 3 & 0.12 & 0.37 & 0.11 & 0.52 \\
\hline Block 4 & 0.42 & 1.00 & 0.52 & - \\
\hline
\end{tabular}

Source: Authors

Table 2 Block densities of the political support network in Malawi

\begin{tabular}{l|l|l|l|l|l|l|l}
\hline & MoF & MoAFS & MoIWD & MoDPC & OPC & DPP & MCP \\
\hline Farm & 0.000 & 0.400 & 0.200 & 0.000 & 0.400 & 0.200 & 0.000 \\
\hline Donor & 0.571 & 0.429 & 0.286 & 0.143 & 0.286 & 0.000 & 0.000 \\
\hline CSO & 0.000 & 0.143 & 0.571 & 0.000 & 0.429 & 0.000 & 0.000 \\
\hline Gov & 0.500 & 0.000 & 0.750 & 0.500 & 0.750 & 0.600 & 0.200 \\
\hline Leg & 0.500 & 0.000 & 0.500 & 0.500 & 0.500 & 1.000 & 1.000 \\
\hline PUB & 0.400 & 0.600 & 0.400 & 0.200 & 0.400 & 0.200 & 0.000 \\
\hline AGIND & 0.000 & 0.167 & 0.333 & 0.000 & 0.333 & 0.167 & 0.000 \\
\hline
\end{tabular}

Source: Own calculations based on simulated support network data

political support among political institutions is also a common feature in industrialized countries, where in addition to lobbying groups, political parties have a high potential for generating electoral support. The potential of donors to generate political support can be explained by the funds donors provide to national governments, which give the governments leeway to generate electoral benefits.

\subsection{Political Influence and Power}

According to our network model of political belief updating, communication structures determine political influence among governmental and nongovernmental organizations. Hence, at a descriptive level, an analysis of the ways in which organizations are influenced by each other is of interest. Beyond a descriptive analysis, it is especially interesting to evaluate the impact of political influence structures on different aspects of political performance. For example, evaluating the extent to which the final policy positions of governmental organizations are influenced by the political views of nongovernmental organizations by measuring the effective participation using political power indices. Or, evaluating the extent to which central organizations take political leadership vis-à-vis civil society in a top-down political process using network multipliers. Moreover, a high political influence exerted by donor organizations would characterize a donor-led policy process, which might undermine political ownership if national stakeholder organizations feel ignored. Furthermore, an analysis of the extent to which the identified political influence and power structures reflect the political expertise of the 
Table 3 Communication network multipliers

\begin{tabular}{l|l|l|l|l|l|l|l|l|l}
\hline & Gov & Leg & PUB & don & Res & AGIND & farm & CSO & Sum \\
\hline MoF & 0.934 & 0.009 & 0.016 & 0.026 & 0.002 & 0.006 & 0.004 & 0.003 & 1.000 \\
\hline MoAFS & 0.736 & 0.002 & 0.063 & 0.076 & 0.012 & 0.036 & 0.052 & 0.025 & 1.000 \\
\hline oMin & 0.832 & 0.027 & 0.041 & 0.032 & 0.010 & 0.018 & 0.013 & 0.028 & 1.000 \\
\hline OBC & 0.645 & 0.030 & 0.051 & 0.067 & 0.036 & 0.030 & 0.067 & 0.074 & 1.000 \\
\hline Leg & 0.181 & 0.733 & 0.038 & 0.012 & 0.006 & 0.007 & 0.011 & 0.012 & 1.000 \\
\hline PUB & 0.108 & 0.007 & 0.727 & 0.059 & 0.012 & 0.056 & 0.019 & 0.012 & 1.000 \\
\hline don & 0.106 & 0.002 & 0.021 & 0.724 & 0.034 & 0.045 & 0.035 & 0.034 & 1.000 \\
\hline Res & 0.091 & 0.003 & 0.064 & 0.107 & 0.530 & 0.063 & 0.050 & 0.091 & 1.000 \\
\hline AGIND & 0.104 & 0.004 & 0.068 & 0.045 & 0.031 & 0.701 & 0.027 & 0.022 & 1.000 \\
\hline farm & 0.096 & 0.003 & 0.055 & 0.047 & 0.031 & 0.034 & 0.700 & 0.034 & 1.000 \\
\hline CSO & 0.135 & 0.004 & 0.038 & 0.063 & 0.086 & 0.034 & 0.061 & 0.579 & 1.000 \\
\hline
\end{tabular}

Source: Own calculations based on own network survey data

involved governmental and nongovernmental organizations is of interest. To assess these interesting questions, we provide a descriptive analysis of the identified political influence and power structures in the following section, and we evaluate the impact of the identified structures on political performance in the next section.

The network multipliers derived from political communication, as described in Chapter "Modeling and Evaluation of Political Processes: A New Quantitative Approach" above, are the centerpiece of our political influence model. Table 3 presents the communication network multipliers that were calculated for specific categories of governmental and nongovernmental organizations.

The network multipliers presented in Table 3 correspond to the aggregated weight of the policy positions of the row category in determining the final policy position of an average individual organization of the column category. For example, the first column presents the average influence of the row categories on the Ministry of Agriculture (MoAFS). As demonstrated in the first row in Table 3, the final policy position of MoAFS after communication is determined $71 \%$ by MoAFS's own initial position; the aggregated weight of the initial position of the donor organizations is $7 \%$ compared to only $2.3 \%$ for the civil society organizations (CSO). Please note that the relatively high own network multipliers on the diagonal of Table 3 result from the high own control of organizations. Hence, political influence exerted via communication is relatively low in the policy domain of CAADP in Malawi, with own network multipliers ranging from 0.52 for the office of the president (OBC) to 0.91 for the Ministry of Finance (MoF). Interestingly, in Malawi, a particularly high own control was reported by governmental organizations, with own control values above $70 \%$ for all organizations expect OBC. Stakeholder organizations are more open to expert information provided by other organizations, with own network multipliers below 65\%. Civil society organizations exhibit a relatively low average own control of 56\% (CSO in Table 3), while interest groups of the agribusiness and farm sectors exhibit a mid-range average own control of approximately $65 \%$. These structures are partially in contrast to the 
influence structures in the European Common Agricultural Policy domain (CAP), where elected governmental organizations are particularly open to learning from nongovernmental organizations that represent relevant interests of their electorate (i.e., in the EU, the average reported own control is below 60\%). In contrast, interest groups involved in CAP decisionmaking reported a comparatively high average own control of over 70\% (Henning 2009); these groups are primarily interested in influencing powerful political actors and less interested in learning about the underlying technological relations. A second interesting feature of the influence structures in Malawi corresponds to the relatively low own control of international donor and national research organizations, with own network multipliers ranging between 66\% and 53\%, respectively (see Table 3). Like public agencies (Pub-AG), these organizations are supposed to be technological leaders with high political knowledge; hence, these organizations should pay less attention to others' organizational point of view. However, Bunda college (BC) reports a particularly low own control of only 54\%. Although public agencies and international donor organizations have significantly higher own control values of $69 \%$ and $66 \%$, respectively, these values are relatively low compared to the values reported by the Ministries. This finding indicates that neither research nor public agencies perceive themselves as strong political experts in the field of agricultural policy and development in Malawi.

Beyond own control, the influence profiles of organizations are interesting. Influence profiles identify influential organizations and describe the extent to which other organizations influence the initial policy position of an organization. Formally, influence profiles can be described by the vector of relative network multipliers that operate as an influence field on an organization. Based on our belief formation model, the influence field operating on an actor is determined by her local communication structures. Hence, the more actors are structurally equivalent in the communication network, the more similar c.p. are their influence fields. Accordingly, we conducted a cluster analysis using the influence profiles of the identified organizations. Based on the reported statistical fit values, we preferred a four cluster solution. As expected, cluster membership corresponds nicely to the identified block model structure (see Table 1). Thus, cluster 1 corresponds to the political core (i.e., block 1), while cluster 3 corresponds to the political periphery (i.e., block 3 ) and the two broker blocks (i.e., blocks 2 and 4) correspond to clusters 2 and 4 , respectively. The specific influence profiles of the clusters are described in Figs. 3 and 4.

Figures 3 and 4 demonstrate that on average, governmental organizations exert the highest influence on other organizations, with an average influence share of $39 \%$, followed by donor organizations, with an average influence share of $18 \%$. On average, agribusiness, farm and civil society interest groups exert only moderate influence on other organizations, with shares ranging from $8 \%$ (IG-AB) to $12 \%$ (IG-farm). A more detailed analysis of the influence of governmental organizations reveals that the main influence on other organizations is exerted by public agencies and other ministries (i.e, MoIWD and MoDPC). In contrast, the central governmental institutions (i.e., MoAFS, MoF and the president) exert little influence on 


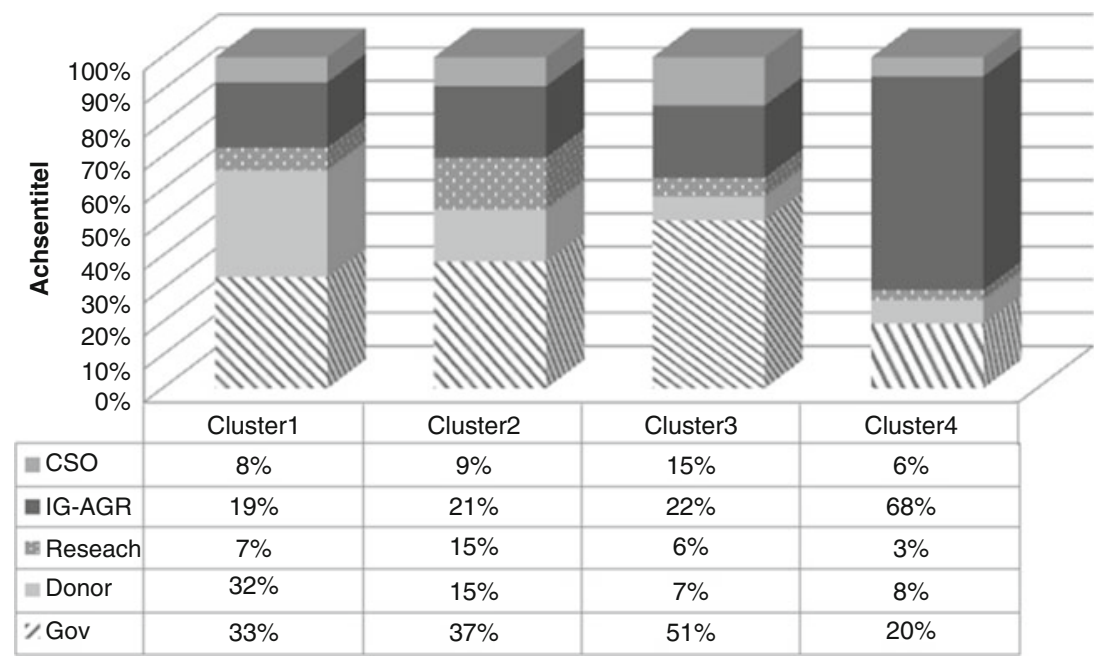

Fig. 3 Influence profiles in the CAADP policy network in Malawi. Source: Authors

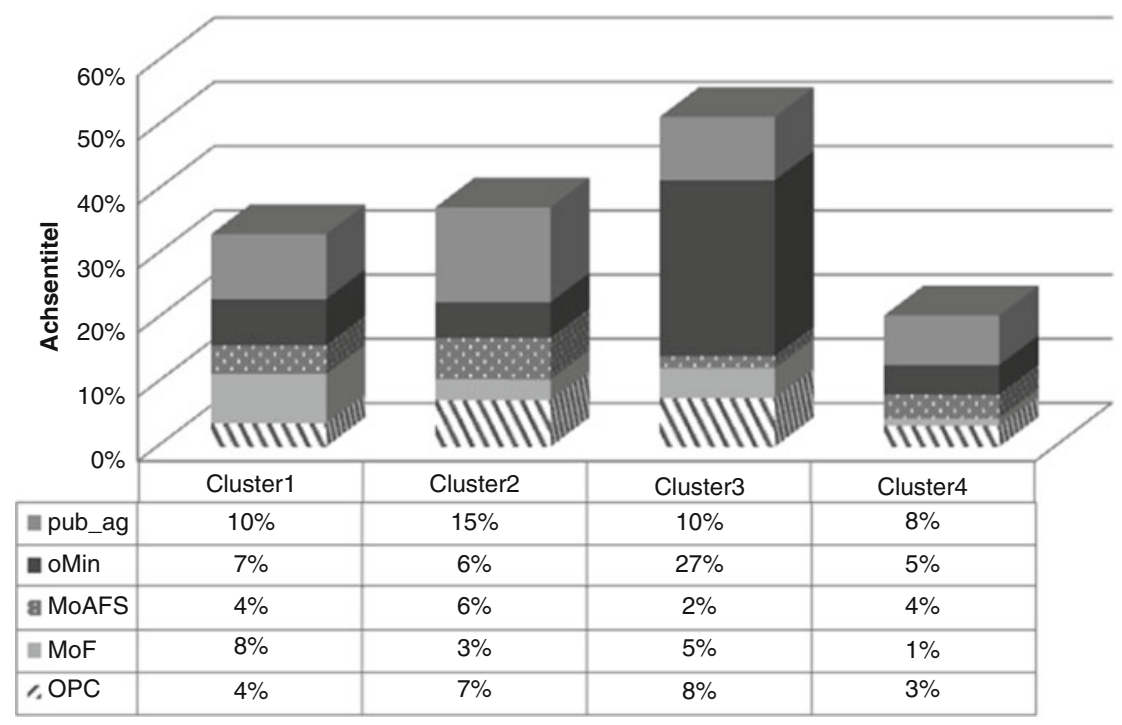

Fig. 4 Relative influence of governmental organizations in profile clusters. Source: Authors

other organizations (see Fig. 4). A comparison of the average influence across clusters reveals interesting characteristic patterns. Cluster 1, which corresponds to the political core, is strongly influenced by donor organizations, with a share of $32 \%$. Governmental organizations have a particularly low influence compared to the average influence in the network, with a share of only $33 \%$ compared to an average of $39 \%$ for all organizations. 
While it is conceivable that donor organizations that represent the majority in the political core primarily influence each other, please note that the MoF is also highly influenced by donor organizations, which have a share of 30\%. Analogously, CISANET and NASFAM, which are both members of cluster 1, are characterized by high influence shares of $31 \%$ and $25 \%$, respectively, for donor organizations.

In contrast, cluster 3, which corresponds to the political periphery (i.e., block 3), is extraordinarily influenced by governmental organizations, with a share of $51 \%$ compared to an average share of $39 \%$ in the entire network. Within governmental organizations, the "other ministries" MoIWD and MoDPC exert a particularly significant influence on the periphery (i.e., cluster 3), with an average share of $27 \%$. Moreover, cluster 3 is the only cluster that is characterized by a significant influence of civil society organizations, with a share of $15 \%$ compared to an average of only $10 \%$ for all organizations. A significantly different influence profile was observed for the most important national farmer organization (i.e., FUM in cluster 4). Cluster 4 is characterized by a particularly high influence of farm organizations, with an average influence share of $55 \%$. Please note that this share includes only the influence of other organizations. Thus, the farm organizations FUM, TAM and CAMAL in cluster 4 are dominantly influenced by other farm organizations. In contrast, governmental and donor organizations have significantly lower influences of $20 \%$ and $8 \%$, respectively, compared to the average influence in the network. Finally, cluster 2 is characterized by an extraordinary influence of national research organizations and a lower influence of public agencies, with an influence share of $15 \%$ for both categories. Moreover, agribusiness has a slightly higher influence on cluster 2 compared to the average of all organizations (see Figs. 3 and 4).

Interestingly, although cluster 2 corresponds to the technical block (i.e., block 2) and includes 2 of the 3 members of block 2, some interesting differences can still be observed. In particular, MoAFS is a member of cluster 2. Hence, although MoAFS is an important member of the political core, the influence field operating on MoAFS differs significantly from the influence field operating on the other core members. First, in contrast to MoF, donor organizations exert comparatively less influence on MoAFS. Instead, agribusiness and farmer interest groups exert a significantly higher influence. Second, domestic research organizations exert more influence on MoAFS than MoF.

Overall, the identified influence structures reveal that governmental actors heavily influence other nongovernmental organizations. Interestingly, the main influence is exerted by the ministries MoIWD and MoDPC and organizations in the political periphery, while none of the central governmental institutions (i.e., MoAFS, MoF or the president [OPC]) exert significant influence on other organizations. Moreover, we found clear evidence for a donor-led policy process, where donors exert influence on the lead ministries MoF and MoAFS. Furthermore, public agencies, particularly ADD, take a technical leadership role, exerting relatively high political influence on the political periphery, including $\mathrm{OBC}$, and on the lead ministries (i.e., MoF and MoAFS) in the political core. In comparison to public agencies and donors, the technical leadership of the national research sector (i.e., $\mathrm{BC}$ ) is less pronounced, with a significant influence on only public agencies and the 
agribusiness organizations in cluster 2 . In contrast, $\mathrm{BC}$ 's influence on the ministries is rather low. From a society perspective, only agribusiness and farm organizations exert political influence; however, these organizations primarily influence themselves. In contrast, with the exception of MoAFS, governmental organizations are not significantly influenced by agricultural interest organizations. Civil society organizations clearly lag behind other organizations and only exert influence in the political periphery, and the parliamentary parties are completely negligible, with only minor relative influence shares below 3\% for nearly all organizations. Thus, in contrast to many parliamentary systems in Western Europe, party leadership of the public political discourse can clearly be denied in Malawi.

It is also important to determine the impact of these specific influence structures on political performance. To answer this question, we must combine the network multiplier with political decisionmaking power to derive the total political power of organizations. As described in Chapter "Whither participation? Evaluating participatory policy processes with the CGPE approach: The case of CAADP in Malawi", we measure political decisionmaking power by applying a composite political bargaining game that includes a modified legislative bargaining game and a modified Grossman and Helpman lobbying game. The solution of the composite game corresponds to a two-step procedure, where we first derive the legislative decisionmaking power of the involved legislators from the modified BF game and subsequently derive the lobbying power of the political agents by applying a generalized political exchange model, as suggested by Pappi and Henning (1998, 1999) and Henning (2009), in a second step. In the modified BF model, legislative power is derived from the set of winning coalitions, where this set is determined by formal constitutional rules and informal legislative norms. By constitution, Malawi is a presidential democracy, where legislative regulations are decided by the parliament under a simple majority rule. By constitution, the president lacks a binding veto power and the government has no binding agenda-setting power vis-à-vis the parliament. Nevertheless, in political practice, the parliament exerts no significant legislative power and is reduced to a pure acclamation machine; the real legislative power rests in the government (Patel and Tostensen 2006). Accordingly, we constructed relevant legislative games, accounting for the dominant role of governmental institutions as legislative norms. However, the literature is ambiguous regarding the specific role of different governmental institutions, namely the power of the involved ministries and the president. Therefore, we constructed different legislative games. In particular, we assumed that agricultural policy in Malawi is decided following the principle of departmental responsibility (PDR) (i.e., MoAFS has agenda-setting power vis-à-vis the cabinet, including the president, and the cabinet decides with a simple majority). Alternatively, in the power scenario PA, we assume that the president functions as a "primus inter pares" in his cabinet (i.e., we assume that the president has agenda-setting power vis-à-vis his cabinet). Furthermore, we assumed that the ministry MoF dominates the political process (i.e., MoF has agenda-setting power vis-à-vis the cabinet [FA]). For all scenarios, we assume that within the cabinet, only the president, MoAFS, MoF and the ministries MoIWD and MoDPC have effective voting power. Please note that 
Table 4 Banzhaf power indices

\begin{tabular}{l|l|l|l|l}
\hline & PDR & PA & FA & PL \\
\hline President & 0.1765 & 0.2941 & 0.1765 & 0 \\
\hline MoAFS & 0.2941 & 0.1765 & 0.1765 & 0 \\
\hline MoF & 0.1765 & 0.1765 & 0.2941 & 0 \\
\hline MoDPC & 0.1765 & 0.1765 & 0.1765 & 0 \\
\hline MoIWD & 0.1765 & 0.1765 & 0.1765 & 0 \\
\hline DPP & 0 & 0 & 0 & 1 \\
\hline MCP & 0 & 0 & 0 & 0 \\
\hline$\sum$ & 1 & 1 & 1 & 1 \\
\hline
\end{tabular}

Source: Calculated by the authors using IOP 2.0 by Thomas Bräuninger and Thomas König

according to interviewed experts, other ministries that are official members of the cabinet play a minor role in the agricultural process. Therefore, these ministries are excluded from our analysis. Finally, in a contrasting scenario, we assume that legislative decisionmaking in Malawi is characterized by party leadership (PL) (i.e., policies are decided by a majority in the parliament, as foreseen in the constitutions, and the government is not involved). Table 4 summarizes the calculated Banzhaf indices for the different constructed legislative scenarios. This table demonstrates that for the 3 government-led scenarios, legislative decisionmaking power is shifted among MoAFS, MoF and the president. In contrast, assuming party leadership, total legislative power is concentrated on the majority party in the parliament (i.e., DPP).

Following Eq. (3), combining legislative decisionmaking power with the political support network multipliers derived from the political support network generates the political decisionmaking power of an organization. In Fig. 6, we present the simulated support network multipliers assuming different support network structures and varying interest of politicians in political support. In particular, we simulated scenarios in which politicians have no, low and high interest in political support, which are labeled as the autarkic, strong and weak state scenarios, respectively, in Fig. 5. Further, we simulated scenarios in which political access is dominated by donor, farm and CSO organizations, which are labeled as donor, farm and CSO lobbying dominance, respectively, in Fig. $5 .^{8}$ Thus, we simulated a total of 4 legislative scenarios for each of the 9 lobbying scenarios. Thus, we simulated a total of 36 political power scenarios, where we used the prediction power of the corresponding political decisionmaking model as a criterion for selecting the empirically relevant model. The best fit to the observed ASWAp decision is achieved by assuming a strong state and donor-dominated lobbying scenario in combination with agenda-setting power for MoAFS (PDR).

\footnotetext{
${ }^{8}$ Technically, we incorporated the dominance of a specific nongovernmental organization category by multiplying the interest in political support provided by the dominating category by 2 and renormalizing accordingly to derive the corresponding support network multipliers.
} 


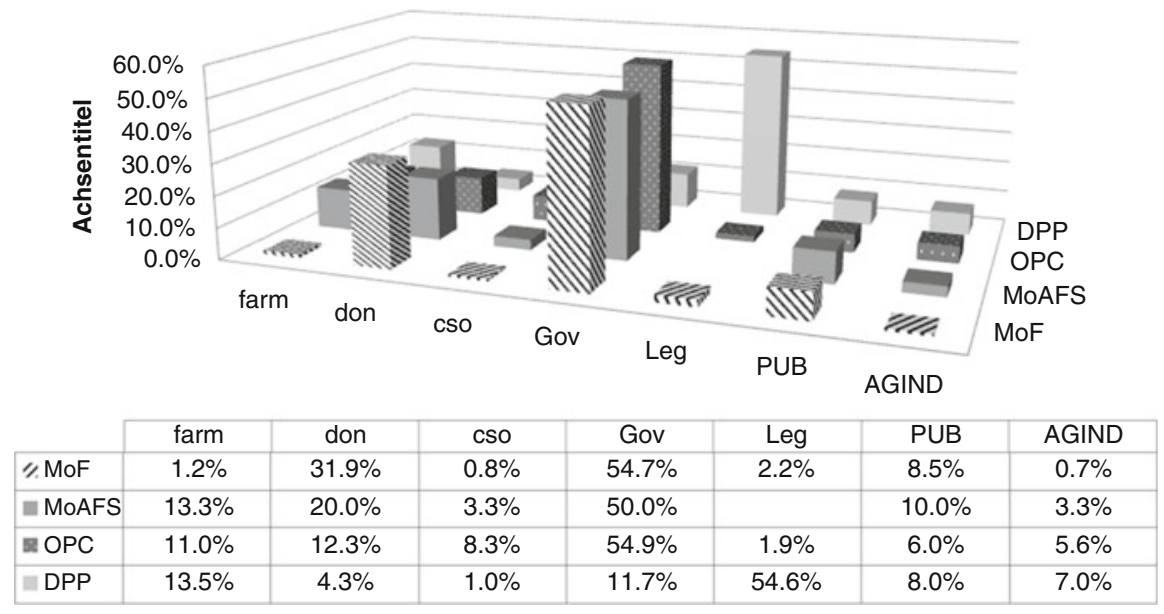

Fig. 5 Network multipliers for the political support network of the CAADP process in Malawi. Source: Authors

In Fig. 5, the support network multipliers for different organizational categories are presented for the empirically best-fit scenario (i.e., assuming a strong state with low politician interest in political support and a political support network that is dominated by international donor organizations). ${ }^{9}$

Figure 5 demonstrates that all governmental organizations, especially $\mathrm{MoF}$ and MoAFS, strongly depend on the political support provided by international donors. Basically, this pattern reflects the fact that the Malawi government depends on the financial resources provided by donor organizations; in exchange, the government is willing to make political compromises favoring the position of the donors. In contrast to the government, the legislative parties rely less on donor support and more on domestic stakeholder organizations, especially farm interest groups. Overall, the average power outflow from governmental and legislative organizations is approximately $55 \%$, which is moderate compared to other political systems (e.g., for the European Union, an average power outflow of $70 \%$ is observed for national members of the agricultural council) (Pappi and Henning 1999).

Following Eqs. (1, 2, and 3), we calculated the total political power by combing the political power derived from the political bargaining game, including lobbying, with the political influence derived from political communication networks. We calculated the total power distribution across organizational categories for the bestfit scenario (i.e., PDR and a donor-dominated lobbying structure) assuming no (i.e., autarkic state), medium (i.e., strong state) and high (i.e., weak state) interest of governmental organizations in political support.

\footnotetext{
${ }^{9}$ Please note that the average network multipliers calculated for all 9 lobbying scenarios do not significantly differ from the values presented in Fig. 5.
} 


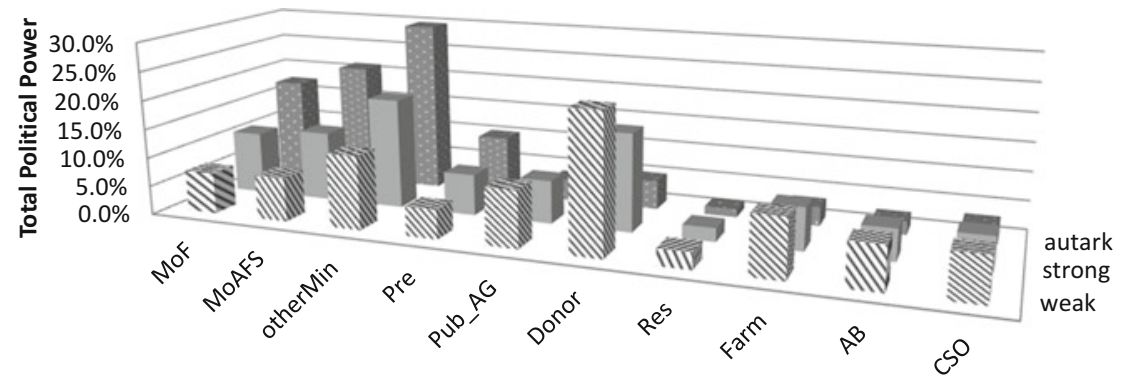

\begin{tabular}{|l|c|c|c|c|c|c|c|c|c|c|}
\cline { 2 - 11 } \multicolumn{1}{c|}{} & MoF & MoAFS & otherMin & Pre & Pub_AG & Donor & Res & Farm & AB & CSO \\
\hline " weak & $7.1 \%$ & $7.6 \%$ & $12.7 \%$ & $5.1 \%$ & $9.7 \%$ & $23.7 \%$ & $2.9 \%$ & $10.0 \%$ & $7.4 \%$ & $7.6 \%$ \\
\hline — strong & $10.8 \%$ & $12.1 \%$ & $19.1 \%$ & $7.1 \%$ & $7.5 \%$ & $16.8 \%$ & $2.3 \%$ & $7.4 \%$ & $5.4 \%$ & $5.8 \%$ \\
\hline E autark & $17.5 \%$ & $21.2 \%$ & $29.8 \%$ & $10.3 \%$ & $3.7 \%$ & $5.0 \%$ & $1.4 \%$ & $3.2 \%$ & $2.3 \%$ & $3.0 \%$ \\
\hline
\end{tabular}

Fig. 6 Total political power distribution in Malawi according to lobbying scenario. Source: Authors

Figure 7 demonstrates that excluding lobbying, the total political power would be highly concentrated on governmental organizations, where MoAFS and MoF are particularly powerful ministries, with individual total powers of $17.5 \%$ and $21.2 \%$, respectively. The other two involved ministries (i.e., MoIWD and MoDPC) are comparatively less powerful as individual institutions, with a joint power of $29.8 \%$. In Fig. 6, we interpreted the $\mathrm{OBC}$ as the institution representing the president. Following this interpretation, for all lobbying scenarios, the president has a significantly lower total political power than the ministries, ranging from only $5.1 \%$ for the weak scenario to $10.3 \%$ for the autarkic scenario. ${ }^{10}$ Without lobbying, the total legislative power outflow from governmental to nongovernmental organizations is relatively low at approximately $20 \%$ (see the autarkic scenario in Fig. 6). Including lobbying power, the outflow increases significantly to $50 \%$ assuming a medium interest in political support (i.e., the strong state scenario) and to nearly $70 \%$ assuming a high interest (i.e., the weak state scenario). Power outflows directed to national stakeholder organizations are even lower, ranging from only $12 \%$ to $34 \%$. International donor organization exhibit nearly the same amount of power outflow as all national stakeholder organizations combined (see Fig. 6). A smaller amount of the total power outflow goes to public agencies that are subordinate to the ministries.

\footnotetext{
${ }^{10}$ In Malawi, a special case occurred in 2010 in which the President of Malawi and the minister of agriculture were present simultaneously. However, in our analyses, we do not focus on persons but on institutions; therefore, we interpreted MoA and the president as two independent corporate actors. Following this interpretation implies different total political power for the president and the MoA, as reported in Fig. 6.
} 


\section{Evaluating Identified Participation Structures}

In this section, we discuss how the identified participation structures impact political performance. In particular, we assess governmental performance by applying the derived indicators to measure political accountability, capture, and ownership and effective use of political knowledge. To evaluate different dimensions of political performance, it is important to define adequate benchmark levels. Because by construction, all indicators lie in the [0-1] interval, 1 is a default benchmark value for all indices. However, for some indices, different benchmark values appear to be more appropriate. For example, when measuring accountability by the total political power of national stakeholder organizations (GA-total), it appears unrealistic to assume that perfect accountability corresponds to a situation in which stakeholders control $100 \%$ of the total power. Depending on the degree to which democratic elections imply incentives for politicians to represent society's interests, the optimal level of accountability induced through stakeholder participation varies. Given a relatively low level of government accountability induced by elections, as is the case in Malawi (see Chapter "Voter Behavior and Government Performance in Malawi: An Application of a Probabilistic Voting Model"), we assume a benchmark value of 0.5 for all three accountability measures. Analogously, when measuring political knowledge used in the policy process by the power share of national research organizations, it also appears adequate to take a benchmark value below 1 . The latter inference results from the fact a benchmark value of 1 implies that the political knowledge of research organizations is infinitely higher than that of other political organizations. Hence, because Bunda College is the only national research organization in Malawi, we took 0.05 as an appropriate benchmark value for our knowledge indicator "PK-research". Finally, when measuring the involvement of national stakeholder organizations in political communication using the network density as an indicator, a benchmark value of 0.5 appears to be more appropriate. Please note that a density of 1 implies that every stakeholder organization communicates with every governmental organization, which would be rather unrealistic and inefficient. This inefficiency results from the fact that brokerage via national peak organizations and subordinated state agencies allows for more efficient communication between government and stakeholder organizations.

Renormalizing the calculated performance indices to the [0-1] interval using appropriate benchmark values, we present the calculated performance indices in an evaluation wheel, as demonstrated in Fig. 7 below. We consider the evaluation wheel a helpful tool for illustrating the impact of the identified participation network structures on the different dimensions of political performance. A closer evaluation of Fig. 7 reveals that overall, the policy process in Malawi implies only a moderate achievement of political performance, where most indicators values reach $50 \%$ or less of their benchmark values (see Fig. 7). At first glance, government capture appears to play only a minor rule in the CAADP policy process in Malawi, with a performance level for total capture (GC-total) reaching over $70 \%$ of the 


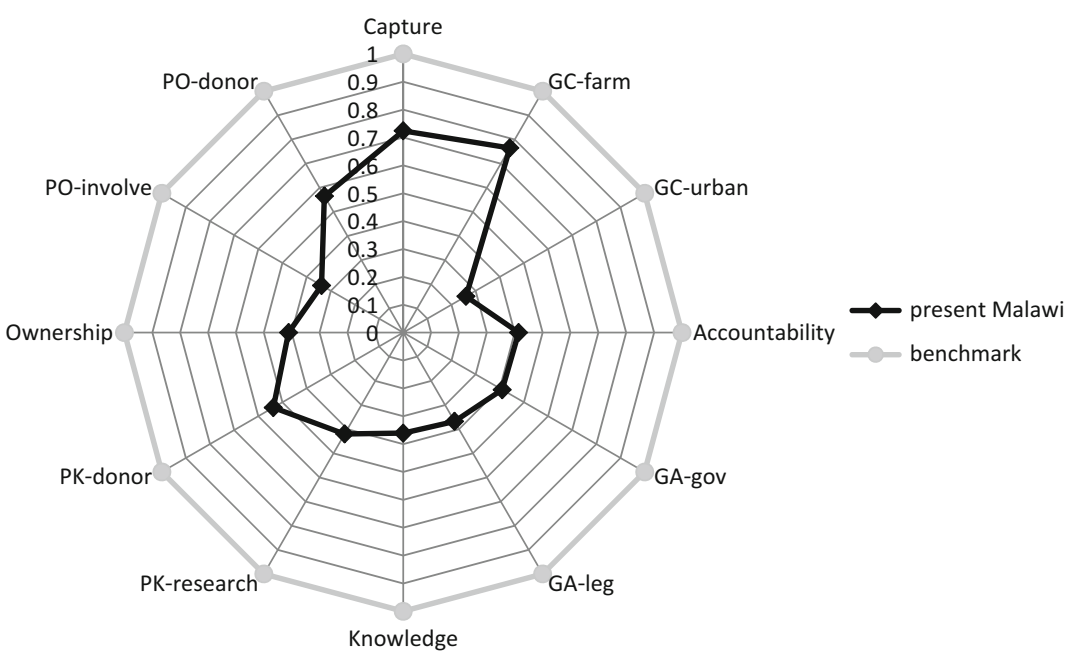

Fig. 7 Participation structures and political performance in the CAADP process of Malawi. Source: Authors

benchmark value, which corresponds to a complete avoidance of capture. However, a close evaluation partially reverses this conclusion. In particular, to construct the capture index, we used the different household types that have been separated in the Malawi CGE (i.e., small-, medium- and large-scale agricultural households and urban consumer households). To calculate the representation of different household types in the political process, we calculated the relative shares of household types in the value-added share of each economic subsector. The higher the value-added share of a subsector that is allocated to a household type, the more the socioeconomic interest groups representing this subsector represent this household type in the political process. Therefore, we matched all agricultural, agribusiness and non-agricultural interest groups in our policy network with economic subsectors. Based on these matches, we could calculate the representation rate of different household types for each organization. Finally, weighting these organizational representation rates by the total power of organizations generates the representation share of a household type in the political process. These shares are compared to the corresponding population shares of household types to derive our capture index. For example, agricultural export crops (i.e., tobacco, coffee and tea) are primarily produced by large-scale farm households (i.e., $30 \%$ of the total value-added share of these sectors ends up in the pocket of large-scale farm households, but only $3 \%$ of all Malawian households are in this household category). Thus, interest groups like TAM, CAMAL and TAMA that focus on representing these subsectors overrepresent large-scale farm households, and general farm organizations, such as FUM, that represent all agricultural subsectors proportionally represent all farm households. A special case corresponds to the National Smallholder Farmers' Association of Malawi (NASFAM), which is focused on representing small- and 
medium-scale farmers. Therefore, we exogenously assume that NASFAM only represents these two household types. Interestingly, overall, medium farm households (e.g., households that operate farms with a size between 0.75 and 3 hectares of land) are extremely underrepresented, as indicated by a difference of approximately 26 percentage points between the population share and the political representation share for this household type. In contrast, urban households are extremely overrepresented in the political process, with the same difference of approximately 26 percentage points between the representation share of urban households and the urban population share. Thus, political participation is clearly biased against rural households and in favor of urban households. This bias can be observed in the relatively low value of the capture sub-indicator GC-urban. In absolute terms, the share of the total political power that represents the interest of urban households is nearly 3 times higher than the urban population share. However, because urban households comprise only 9\% of all Malawian households, the total capture remains low.

Finally, we would like to make one further comment on the interpretation of the impact of the identified participation structures on the achievement of a political consensus. Compared to the benchmark level of 1, the current participation structures imply only a moderate potential for generating a political consensus, as indicated by a level of $41 \%$ for the central ownership indicator Ownership. However, as demonstrated in Fig. 8, political communication implies a remarkable reduction of political conflict in the complete network. This reduction is demonstrated in Fig. 8, which compares the range of the convex hull that covers all preferred policy positions before and after communication (see the outer and medium set, respectively, in Fig. 8). Moreover, Fig. 8 demonstrates that the

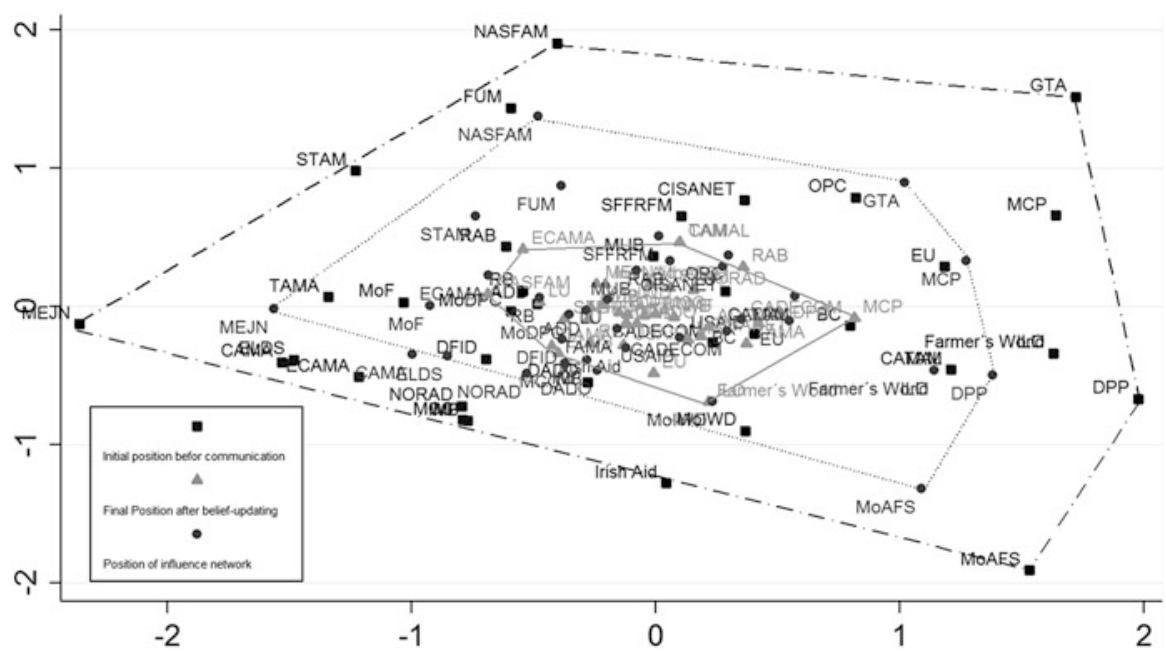

Fig. 8 Participation structures and political consensus in the CAADP process of Malawi. Source: Authors 
influence fields that operate on the different organizations imply extremely homogenous policy positions (see the set covering the inner dots in Fig. 8). Thus, if governmental organizations were more open to the opinions and viewpoints that other organizations communicate in the political discourse, the communication network structure in Malawi would imply a political consensus. Therefore, an evaluation of the identified communication structures against a benchmark of 1 might lead to result that is too pessimistic with regard to the potential to achieve political ownership via political consensus.

\section{From Diagnosis to Therapy: Lessons Concerning Efficient Design of Participatory Policy Processes}

To identify potential strategies for improving participatory and evidence-based policy processes, we simulated the variation of political performance indicators assuming changed formal and informal rules determining participation structures. We simulated political performance for all 45 legislative and lobbying scenarios; however, in the following section, we focus on the most relevant results. First, for both types of participation, we change the level of participation intensity without changing the participation structure. With respect to lobbying, the level of politician interest in political support is changed, keeping both the relative interests of politicians and the access to politicians constant. Accordingly, with respect to political communication, we change the level of own control of politicians, keeping the communication network structure and the relative own control among politicians constant. Second, we change the participation structure (i.e., we shift the participation bias from the identified donor-dominated participation structure to a CSO- and farm-dominated participation structure. Finally, we simulated how political performance changes assuming a constitutional reform from the present PDR to party leadership. We present the results for these four scenarios in Fig. 9. In detail, it is assumed in the "no lobby scenario" that politicians have no interest in political support. In contrast, improved access of national stakeholder organizations is simulated in the "CSO lead" scenario. Technically, the latter scenario is generated by recalculating the support network multipliers under the assumption that the relative interest of politicians in political support provided by national stakeholder organizations ${ }^{11}$ is increased. In the "open discourse scenario," we multiplied the own control of politicians by 0.7 and recalculated the communication network multipliers. Finally, in the "party leadership" scenario, we simulated a constitutional reform of the legislative process from the PDR to party leadership (PL). Please note that with respect to content, such a reform might correspond to a formal constitutional reform from a presidential to a parliamentary system. However, such

\footnotetext{
${ }^{11}$ Compared to the best-fit scenario, we multiplied the interest in political support of national stakeholders by 2 and divided the interest in support of donor organizations by 2 .
} 


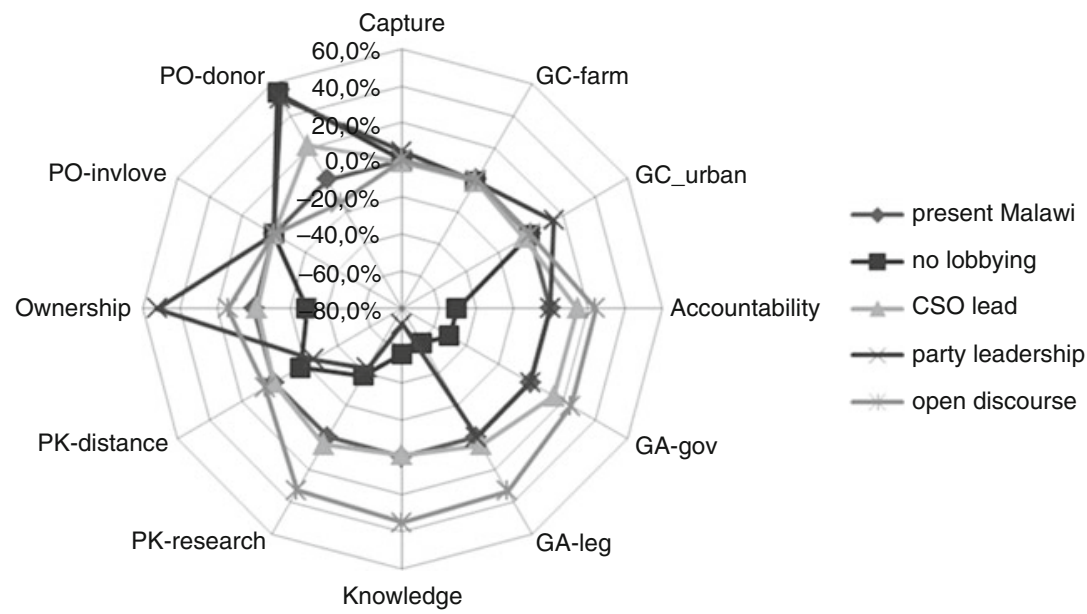

Fig. 9 The impact of changed participation structures on political performance in Malawi, as indicated by percent change in comparison to the base-run scenario. Source: Authors

a reform might also result from changed legislative norms without a formal change of the constitution. ${ }^{12}$

For all simulation scenarios, we take the best-fit scenario (see Fig. 7) as a baserun scenario and present the percent change in political performance indicators in comparison to their corresponding values in the base-run in Fig. 9.

As demonstrated in Fig. 8, lobbying has a significant positive impact on nearly all political performance indicators. Only the dominance of international donor organizations is less pronounced assuming no lobbying occurs (i.e., without lobbying, international stakeholder organizations would not be able to gain much political influence, and Malawi's civil society would take more ownership in CAADP reforms due to a feeling that these reforms are less imposed by the international donor community). However, as demonstrated in Fig. 9, without lobbying, the final political decision regarding CAADP would also be more distant to the desires of Malawi civil society, implying a lower political consensus and less political ownership, as indicated by a decrease of approximately $30 \%$ in the indicator Ownership for the "no lobbying scenario" (see Fig. 9). Moreover, increasing the importance of lobbying without changing the relative lobbying power of organizations implies that there will be no impact on capture. Accordingly, for the no lobbying scenario, all capture indices remain unchanged in comparison to their base-run values. The main positive impacts of increased participation via lobbying can be observed for the effective use of political knowledge and for accountability. The use of political

\footnotetext{
${ }^{12}$ By constitution, even in most presidential systems, the official legislative power resides entirely in the parliament.
} 
knowledge decreased by nearly $60 \%$ when comparing the no lobby scenario to the base-run scenario (see Fig. 9).

Analogously, government accountability increases significantly with lobbying, with the accountability level decreasing by approximately $50 \%$ for the no lobbying scenario compared to the base-run scenario (see Fig. 9). Interestingly, the positive impact of lobbying does not change significantly if different lobby structures are assumed. Hence, as demonstrated in Fig. 9, for the CSO scenario, the majority of performance indicators remain unchanged (e.g., they lie on the $0 \%$ line in Fig. 9). The only exemptions are accountability (GA-total), which improves by $20 \%$, and the dominance of donor organization (PO-donor), which is significantly reduced when changing form donor-dominated to CSO- or farm-dominated lobbying structures. $^{13}$

As described above, the high own control of politicians is a characteristic feature of the CAADP policy process in Malawi, which implies that politicians rely primarily on their own expertise when making policy choices. As demonstrated in Fig. 9, increasing the importance of public discourse for the political belief updating of politicians would imply that wisdom of the crowd effects can be better exploited in Malawi. Thus, in particular, the effective use of political knowledge would increase significantly. Please note that in this context, increasing the physical participation of stakeholders fails to automatically guarantee higher political influence of stakeholders because the political influence of stakeholders only results if politicians in fact update their beliefs based on the political views and opinions communicated by national stakeholders. Thus, as long as stakeholder participation is only formally imposed, as is partially true for the CAADP process in Malawi, the impact on performance is rather limited. A change in the political culture such that politicians increasingly consider the potential political expertise of national stakeholders is needed. However, in this context, a warning also appears necessary. An increase in the effective participation of national stakeholders in political communication only triggers wisdom of the crowd effects and improves political performance if stakeholders have a relatively high political knowledge in comparison to their total political power. Our analysis indicates that this scenario is relevant for Malawi, but this scenario does not necessarily hold true for other countries.

Finally, shifting legislative power from the government to the parliament implies a trade-off between increased political ownership and sharply decreased effective use of political knowledge. In contrast, political incentives (i.e., accountability and capture) are only slightly changed by this power shift (see the party leadership scenario in Fig. 9). Basically, this result follows from the fact that in contrast to governmental organizations, parliamentary parties have significantly less political knowledge (see Fig. 10 in the appendix). Hence, although these parties are generally more open to political opinions communicated by other organizations in the political discourse (i.e., parties have a lower own control), the overall effect of this

\footnotetext{
${ }^{13}$ Please note, however, that shifting the dominance from donor to farm organizations has a positive impact on government capture, as farmers are better represented.
} 
scenario is negative in Malawi. In contrast, party leadership has a strong positive impact on political ownership. First, deciding budget allocations for CAADP policy programs under a party leadership implies that these allocations would be much closer to the allocations preferred by civil society organizations (i.e., political ownership in CAADP reforms would significantly increase), as indicated by a nearly $60 \%$ increase in the indicator Ownership (see Fig. 9). Moreover, the political power exerted by international donor organizations would be significantly lower for the party leadership scenario than for the base-run scenario. Thus, under party leadership, the civil society of Malawi would be less likely to perceive that CAADP reforms are imposed by international donors.

\section{Conclusion}

Although participatory and evidence-based policy processes are increasingly promoted at the academic level and in political practice, the current understanding of the impact of these processes on political performance is still in its infancy. In this context, this paper proposes a network-based framework for analyzing and evaluating participatory and evidence-based policy processes. Specifically, we consider the following points to be the main contributions of our approach:

1. The approach is theoretically founded. In particular, we derive our theoretical framework by incorporating a network model of political belief formation into a political bargaining model of the Baron-Grossman-Helpman type (BGH). The latter model combines a generalized Grossman-Helpman lobbying model and a modified legislative bargaining model of the Baron and Ferejohn type. The central component of this integrated model corresponds to a generalized mean voter decision-rule, where in addition to legislators, interest groups also have political control over policies (Pappi and Henning 1998; Henning 2000, 2009). Within our approach, the political control of nongovernmental organizations results from two different mechanisms: lobbying and communication learning. The first mechanism is determined by the political access structures by which nongovernmental organizations access powerful governmental organizations, and the second mechanism is determined by political communication among organizations.

2. Our approach is empirically applicable, where the equilibrium outcome of the extended BGH-model can be derived from observed political support and communication networks. Technically, political decisions are determined by three components in equilibrium: constitutional rules and legislative norms captured by legislative decisionmaking power indices, political access structures captured by support network multipliers and political communication structures captured by communication network multipliers. Accordingly, standard social network tools, such as block modeling, can first be applied to describe basic participation structures quantitatively. Second, innovative network-based tools (i.e., network multipliers and total political power) are derived to describe essential participatory structures. 
3. Further, based on our model, political performance indicators can be theoretically derived and empirically measured. In particular, based on the empirical application of our approach to the CAADP reform process in Malawi, we can draw the following general conclusions regarding the impact of participation structures on political performance:

a. Political performance is a multidimensional concept that includes wellestablished governmental incentive problems (i.e., governmental accountability and capture), as reported in the political economy literature. In addition, the lack of political ownership that corresponds to an incentive problem of the society or to the lack of political knowledge is another important source of policy failure.

b. We demonstrated that a trade-off typically exists between different aspects of political performance (i.e., a participation structure favoring one specific aspect of political performance simultaneously impedes another). For example, in Malawi, we found a trade-off between political ownership and the use of political knowledge, shifting the legislative power from the government to the legislative parties. Moreover, the high political influence of international donor organizations increases the use of political knowledge but simultaneously decreases political ownership.

c. The impact of participation structures on political performance depends on specific framework conditions (i.e., the same structure can enhance political performance in one country and impede performance in another). For example, an increase in the political influence of national civil society organizations via lobbying or political communication has a significant positive impact on the effective use of political knowledge in Malawi. However, this positive impact depends on the fact that in Malawi, national stakeholders have relatively high political knowledge in comparison to their actual political influence. Accordingly, no blueprint participation structures are optimal for all countries.

4. Because our approach is theoretically founded, we can perform simulations to identify participation structures that imply higher political performance. However, a concrete strategy for implementing the identified improved participation structures in political practice cannot yet be derived from our approach. With respect to changed policy network structures, such a strategy demands a theory that explains the network-generating process. We address this very interesting topic in Chapter "The Formation of Elite Communication Networks in Malawi: A Bayesian Econometric Approach". However, beyond network structures, participation is also determined by the own control and interest in political support of politicians. Improving our understanding of the determinants of these components is an interesting topic that we leave for future work.

5. Finally, we must admit that the relevance of our assessments to political practice depends on the assumption that our theoretical model correctly describes political decisionmaking in real political systems. In this regard, we use the prediction power of our approach to assess its empirical relevance. With respect to the CAADP reform in Malawi, our best-fit specification nicely predicts the empirically observed budget allocations, with an average prediction error below $20 \%$. 


\section{Appendix}

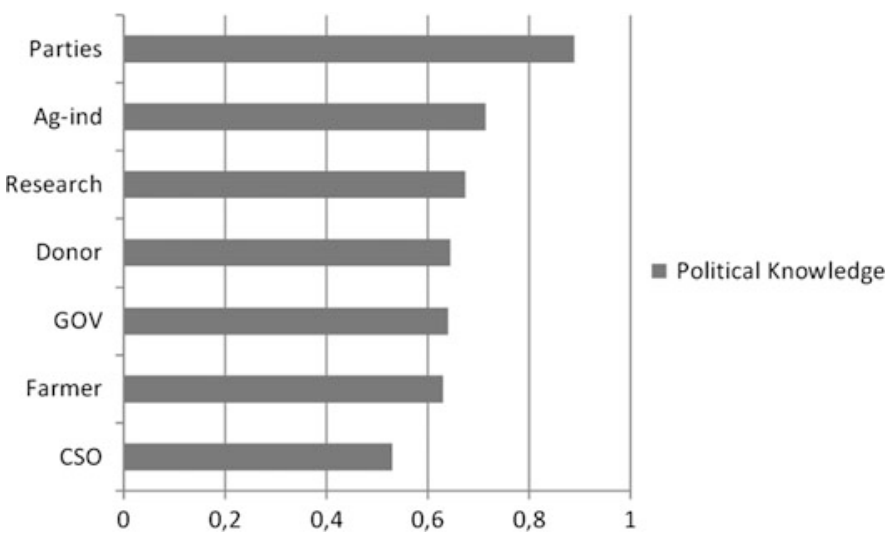

Fig. 10 Average political knowledge in Malawi according to organizational category. Source: Authors

Table 5 Organizations in Malawi: acronym, type and name

\begin{tabular}{|c|c|c|c|c|c|}
\hline Acronym & Type & Name & Reputation & Block & Cluster \\
\hline MoF & GOV & Ministry of Finance & 0.79 & 1 & 1 \\
\hline MoAFS & GOV & $\begin{array}{l}\text { Ministry of Agriculture and Food } \\
\text { Security }\end{array}$ & 1.00 & 1 & 2 \\
\hline MoIWD & GOV & $\begin{array}{l}\text { Ministry of Irrigation and Water } \\
\text { Development }\end{array}$ & 0.67 & 2 & 3 \\
\hline MoDPC & GOV & $\begin{array}{l}\text { Ministry of Dev. Planning and } \\
\text { Cooperation }\end{array}$ & 0.45 & 3 & 3 \\
\hline $\mathrm{RB}$ & PUB & Reserve Bank & 0.27 & 3 & 1 \\
\hline OPC & GOV & $\begin{array}{l}\text { Office of the President and the } \\
\text { Cabinet }\end{array}$ & 0.48 & 3 & 3 \\
\hline SFFRFM & PUB & $\begin{array}{l}\text { Smallholder Farmers Fertilizer } \\
\text { Revolving Fund }\end{array}$ & 0.45 & 3 & 3 \\
\hline LU & PUB & Logistics Unit & 0.30 & 3 & 1 \\
\hline DPP & LEG & Democratic Progressive Party & 0.70 & 3 & 3 \\
\hline MCP & LEG & Malawi Congress Party & 0.33 & 3 & 3 \\
\hline ADD & PUB & Agricultural Development Divisions & 0.67 & 2 & 2 \\
\hline DADO & PUB & $\begin{array}{l}\text { District Agricultural Development } \\
\text { Offices }\end{array}$ & 0.52 & 3 & 3 \\
\hline DFID & DON & $\begin{array}{l}\text { Department for International Devel- } \\
\text { opment UK }\end{array}$ & 0.82 & 1 & 1 \\
\hline Irish Aid & DON & Irish Aid & 0.67 & 1 & 1 \\
\hline NORAD & DON & $\begin{array}{l}\text { Norwegian Agency for Dev. } \\
\text { Cooperation }\end{array}$ & 0.58 & 1 & 1 \\
\hline
\end{tabular}


Table 5 (continued)

\begin{tabular}{|c|c|c|c|c|c|}
\hline Acronym & Type & Name & Reputation & Block & Cluster \\
\hline USAID & DON & USAID & 0.73 & 1 & 1 \\
\hline EU & DON & EU & 0.85 & 1 & 1 \\
\hline IMF & DON & International Monetary Fund & 0.55 & 1 & 1 \\
\hline WB & $\mathrm{DON}$ & World Bank & 0.82 & 1 & 1 \\
\hline $\mathrm{BC}$ & RES & Bunda College & 0.82 & 2 & 2 \\
\hline FW & IG-AB & Farmer's World & 0.55 & 1 & 3 \\
\hline ILO & IG-AB & Ilovo Sugar & 0.33 & 3 & 3 \\
\hline RAB & IG-AB & Rab Processors & 0.27 & 3 & 2 \\
\hline STAM & IG-AB & Seed Trade Association of Malawi & 0.61 & 1 & 1 \\
\hline MUB & IG-AB & Mulli Bros. & 0.52 & 3 & 1 \\
\hline GTA & IG-AB & Grain Trader Association & 0.61 & 3 & 2 \\
\hline FUM & IG-farm & Farmers Union Malawi & 0.79 & 4 & 4 \\
\hline NASFAM & IG-farm & $\begin{array}{l}\text { National Smallholder Farmers' Ass. } \\
\text { of Malawi }\end{array}$ & 0.73 & 3 & 1 \\
\hline CISANET & IG-CSO & CISANET & 0.58 & 1 & 1 \\
\hline TAM & IG-AB & Tea Association of Malawi & 0.52 & 3 & 4 \\
\hline TAMA & IG-AB & Tobacco Association Malawi & 0.52 & 3 & 2 \\
\hline MEJN & IG-NAG & Malawi Economic Justice Network & 0.55 & 3 & 3 \\
\hline ECAMA & IG-NAG & Economics Association of Malawi & 0.39 & 3 & 3 \\
\hline CAMA & IG-Con & Consumers Association of Malawi & 0.52 & 3 & 3 \\
\hline MCC & IG-Chur & Malawi Council of Churches & 0.39 & 3 & 1 \\
\hline ELDS & IG-Chur & Evangelical Lutheran Development & 0.36 & 3 & 3 \\
\hline CADECOM & IG-Chur & Catholic Development Commission & 0.55 & 3 & 2 \\
\hline
\end{tabular}

Source: Calculated by authors from own survey data

Notes: GOV: Government, IG- (AB: Agribusiness, farm: Farmers, CSO: Civil society or private sector organization, NAG: Non-Agrar, Con: Consumers Associations, Chur: Churches), PUB: Public sector agency or local government organization, LEG: Political party, DON: Donor organizations, RES: Research organizations

\section{References}

Aberman, N.-L., M. Johnson, K. Droppelmann, E. Schiffer, R. Birner, and P. Gaff. 2012. Mapping the Contemporary Fertilizer Policy Landscape in Malawi. IFPRI Discussion Paper 01204. Washington, DC: International Food Policy Research Institute.

Adserà, A., C. Boix, and M. Payne. 2003. Are You Being Served? Political Accountability and Quality of Government. The Journal of Law, Economics and Organization 19 (2): 445-489.

Ball, R. 1995. Interest Groups, Influence and Welfare. Economics and Politics 7 (2): 119-146.

Bardhan, P., and D. Mookherjee. 2002. Relative Capture of Local and Central Governments: An Essay in the Political Economy of Decentralization. Working Paper C99-109. Center of International and Development Economics Research (CIDER).

Beilhartz, H.-J., and H. Gersbach. 2004. General Equilibirium Effects and Voting into a Crisis. CEPR Discussion Paper 4454. London: Centre for Economic Policy Research. 
Birner, R., and D. Resnick. 2010. The Political Economy of Policies for Smallholder Agriculture. World Development 38 (10): 1442-1452.

Bischoff, I., and L.-H. Siemers. 2011. Biased Beliefs and Retrospective Voting: Why Democracies Choose Mediocre Policies. Public Choice 156: 163-180.

Caplan, B. 2007. The Myth of the Rational Voter-Why Democracies Choose Bad Politics. Princeton, NJ: Princeton University Press.

Chambote, R., and A. Shankland. 2011. Country Ownership, Stakeholder Participation and the Political Economy of Priority-Setting in the Mozambique Pilot Program for Climate Resilience. Mozambique Case Study Report. Brighton: Institute of Development Studies.

Coleman, J.S. 1990. Foundation of Social Theory. Cambridge: Harvard University Press.

Henning, C.H.C.A. 2000. Macht und Tausch in der europäischen Agrarpolitik: Eine positive politische Entscheidungstheorie. Campus: Frankfurt/Main.

. 2009. Networks of Power in the CAP System of the EU-15 and EU-27. Journal of Public Policy 29(Special Issue 02):153-177.

Henning, C.H.C.A., and A. Wald. 2000. Zur Theorie der Interessenvermittlung: Ein Netzwerkansatz dargestellt am Beispiel der gemeinsamen Europäischen Agrarpolitik. Politische Vierteljahreszeitschrift 41 (4): 647-676.

Jones, H. 2013. Building Political Ownership and Technical Leadership. Cambodia: Cambodia Association Centre for Policy Studies.

Keefer, P., and S. Khemani. 2005. Democracy, Public Expenditures, and the Poor: Understanding Political Incentives for Providing Public Services. The World Bank Research Observer 20 (1): $1-27$.

Knoke, D., F.U. Pappi, J. Broadbent, and Y. Tsujinaka. 1996. Comparing Policy Networks: Labor Politics in the U.S., Germany, and Japan. New York: Cambridge University Press.

Laumann, E.O., and D. Knoke. 1987. The Organizational State. Madison, WI: University of Wisconsin Press.

Laumann, E.O., P. Marsden, and D. Prensky. 1989. The Boundary Specification Problem in Network Analysis. In Research Methods in Social Network Analysis, ed. L.C. Freeman, D.R. White, and A.K. Romney, 61-87. Fairfax, VA: George Mason University Press.

NEPAD. 2010. The Comprehensive Africa Agriculture Development Programme (CAADP). http://www.nepad-caadp.net/about-caadp.php. Accessed 16 Oct 2013.

Pappi, F.U., and C.H.C.A. Henning. 1998. Policy Networks: More than a Metaphor? Journal of Theoretical Politics 10 (4): 553-575.

- 1999. The Organization of Influence on EC's Common Agricultural Policy: A Network Approach. European Journal of Political Research 36 (2): 257-281.

Pappi, F.U., T. König, and D. Knoke. 1995. Entscheidungsprozesse in der Arbeits- und Sozialpolitik. Frankfurt/Main: Campus.

Patel, N., and A. Tostensen. 2006. Parliamentary-Executive Relations in Malawi 1994-2004. Working Paper WP 2006: 10. Norway: Chr. Michelsen Institute.

Randall, I. 2011. Guidelines for Non State Actor Participation in CAADP Processes. Midrand: Wasafiri Consulting.

Sabatier, P.A., and H.C. Jenkins-Smith. 1993. Policy Change and Learning-An Advocacy Coalition Approach. Boulder, CO: Westview Press.

The Ministry of Agriculture and Food Security, Republic of Malawi. 2010. Agriculture Sector Wide Approach (ASWAp). Malawi's Prioritised and Harmonised Agricultural Development Agenda. http://www.caadp.net/pdf/Investment\%20plan\%20-\%20Malawi.pdf. Accessed 16 Oct 2013.

Wasserman, S., and K. Faust. 1994. Social Network Analysis: Methods and Applications. Cambridge, MA: Cambridge University Press.

World Bank. 2011. Participation at Project, Program and Policy Level. http://go.worldbank.org/ HKL3IU1T21. Accessed 16 Oct 2013. 
Christian Henning is professor and chair of agricultural economics, University of Kiel (Germany). He studied economics, agricultural economics, sociology, political science and mathematics. He earned a $\mathrm{PhD}$ in economics, in agricultural economics and in political science. His main areas of specialization are applied political economy and applied economic modelling of agricultural policies. To date he has published five books and various articles in refereed journals including PLoS ONE, American Journal of Agricultural Economics, European Review of Agricultural Economics, Journal of Public Policy, Journal of Mathematical Sociology and Journal of Theoretical Politics.

Eva Krampe is an agricultural sector expert at the European Investment Bank. She studied agricultural economics and earned a PhD in agricultural economics at the University of Kiel (Germany). Her main areas of specialization are Agricultural Policies in the European Union and Sub-Saharan Africa, Applied Political Economy, Agriculture Value Chain Finance, and Economic Analysis of Agricultural Investment Projects.

Open Access This chapter is licensed under the terms of the Creative Commons Attribution 4.0 International License (http://creativecommons.org/licenses/by/4.0/), which permits use, sharing, adaptation, distribution and reproduction in any medium or format, as long as you give appropriate credit to the original author(s) and the source, provide a link to the Creative Commons license and indicate if changes were made.

The images or other third party material in this chapter are included in the chapter's Creative Commons license, unless indicated otherwise in a credit line to the material. If material is not included in the chapter's Creative Commons license and your intended use is not permitted by statutory regulation or exceeds the permitted use, you will need to obtain permission directly from the copyright holder.

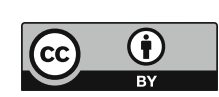

